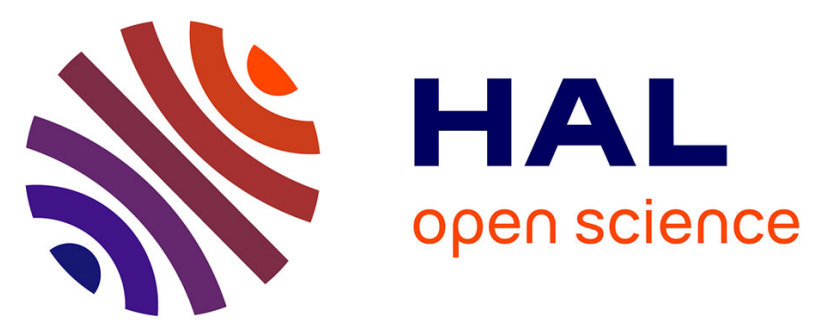

\title{
Instability Mechanism of Roll/Lateral Biodynamic Rotorcraft-Pilot Couplings
}

\author{
Vincenzo Muscarello, Pierangelo Masarati, Giuseppe Quaranta, Georges Tod, \\ Julien Gomand, François Malburet, Marilena D. Pavel
}

\section{To cite this version:}

Vincenzo Muscarello, Pierangelo Masarati, Giuseppe Quaranta, Georges Tod, Julien Gomand, et al.. Instability Mechanism of Roll/Lateral Biodynamic Rotorcraft-Pilot Couplings. Journal- American Helicopter Society, 2018, 63 (2), pp.1-13. 10.4050/jahs.63.022004 . hal-02362767

\section{HAL Id: hal-02362767 https://hal.science/hal-02362767}

Submitted on 14 Nov 2019

HAL is a multi-disciplinary open access archive for the deposit and dissemination of scientific research documents, whether they are published or not. The documents may come from teaching and research institutions in France or abroad, or from public or private research centers.
L'archive ouverte pluridisciplinaire HAL, est destinée au dépôt et à la diffusion de documents scientifiques de niveau recherche, publiés ou non, émanant des établissements d'enseignement et de recherche français ou étrangers, des laboratoires publics ou privés. 


\title{
Instability Mechanism of Roll/Lateral Biodynamic Rotorcraft-Pilot Couplings
}

\author{
Vincenzo Muscarello* Pierangelo Masarati Guaranta \\ Department of Aerospace Science and Technology, Politecnico di Milano, Milano, Italy \\ Georges Tod Julien Gomand François Malburet \\ École Nationale Supérieure d'Arts et Métiers, Aix en Provence, France \\ Marilena D. Pavel \\ Faculty of Aerospace Engineering, Delft University of Technology, Delft, The Netherlands
}

\begin{abstract}
The paper investigates the basic mechanism of aeroservoelastic pilot-assisted oscillation about the roll axis due to the interaction with pilot's arm biomechanics. The motivation stems from the observation that a rotor imbalance may occur as a consequence of rotor cyclic lead-lag modes excitation. The work shows that the instability mechanism is analogous to air resonance, in which the pilot's involuntary action plays the role of the automatic flight control system. Using robust stability analysis, the paper shows how the pilot's biodynamics may involuntarily lead to a roll/lateral instability. The mechanism of instability proves that the pilot biodynamics is participating in the destabilization of the system by transferring energy, i.e., by producing forces that do work for the energetically conjugated displacement, directly into the flapping mode. This destabilizes the airframe roll motion, which, in turn, causes lead-lag motion imbalance. It is found that, depending on the value of the time delay involved in the lateral cyclic control, the body couples with rotor motion in a different way. In the presence of small or no time delays, body roll couples with the rotor through the lead-lag degrees of freedom. The increase of the time delay above a certain threshold modifies this coupling: The body no longer couples with the rotor through lead-lag but directly through flap motion.
\end{abstract}

\section{Nomenclature}

$a_{Y}^{\text {seat }}$
$\mathbf{B}(\mathbf{p})$
$\mathbf{C}(\mathbf{p})$
$\mathbf{D}$
$f_{n}$
$G_{Y}$
$G_{1 C}$

$H_{\text {nom }}(s, \mathbf{p})$

$H_{P P}(s)$

$H_{\mathrm{YC}}(s, \mathbf{p}), H_{\mathrm{YS}}(s, \mathbf{p})$

$\Im(\cdot)$

$\mathrm{j}$

$\mathbf{K}(\mathbf{p})$

$\mathbf{M}(\mathbf{p})$

$\mathbf{P}_{C}^{(k)}$

$\mathbf{P}_{K}^{(k)}$

$\mathbf{P}_{M}^{(k)}$

p

q

$q_{0}^{(k)}$

$R$

$\Re(\cdot)$

$T_{p}$

$T_{z}$

$\operatorname{deg} / \%$

imaginary part

imaginary unit

model

real part $\mathbf{u}$

$y$

$\alpha_{Y}, \alpha_{X}$

$\alpha^{(k)}$

$\beta_{1 C}, \beta_{1 S}$

$\beta^{(k)}$

output matrix of the helicopter model

off-diagonal driving force

loop transfer function gain

gearing ratio between lateral control inceptor

displacement and blade cyclic pitch rotation,

nominal loop transfer function

structural pilot model transfer function, $\% / g$

helicopter transfer functions, $\mathrm{m} \cdot \mathrm{s}^{-2} \cdot \mathrm{rad}^{-1}$

stiffness matrix of the helicopter model

mass matrix of the helicopter model

damping force-phasing matrix for the $k$ th mode

stiffness force-phasing matrix for the $k$ th mode

mass force-phasing matrix for the $k$ th mode

vector of trim parameters of the helicopter

state vector of the helicopter model

initial condition coefficient for the $k$ th mode

main rotor radius, $\mathrm{m}$

structural pilot model real pole time constant, $\mathrm{s}$ structural pilot model zero time constant, $\mathrm{s}$

$\gamma^{(k)}$

$\delta_{Y}$

$\zeta_{1 C}, \zeta_{1 S}$

$\vartheta_{1 C}, \vartheta_{1 S}$

$\lambda_{k}$

$\mu_{P}$

$\xi$

$\tau_{Y}$

$\boldsymbol{\phi}^{(k)}$

$\Omega$

$\omega_{n}$

(.)

$(\cdot)^{\prime}$ input vector of the helicopter model output vector of the helicopter model body pitch and roll angles coefficients for the mass force-phasing matrix main rotor cyclic flap angles coefficients for the damping force-phasing matrix

coefficients for the stiffness force-phasing matrix

lateral cyclic control inceptor rotation, $\%$

main rotor cyclic lead-lag angles

main rotor cyclic pitch angles

generic $k$ th eigenvalue

structural pilot model gain, $\% / g$

structural pilot model complex poles damping

factor

loop transfer function time delay, s

generic $k$ th eigenvector

main rotor angular speed, $\mathrm{rad} / \mathrm{s}$

structural pilot model complex poles frequency, $\mathrm{rad} / \mathrm{s}$

time derivative, $\mathrm{d} / \mathrm{d} t$

azimuthal derivative, $d / d \psi$

\section{Introduction}

Adverse interactions between rotorcraft dynamics and human pilot belong to the challenging area of rotorcraft-pilot couplings (RPCs). These phenomena occur when the pilot introduces an inadvertent or unintentional command in the control system as a consequence of the vehicle dynamics, resulting in oscillatory or divergent motion, difficulty in performing the desired tasks, and, ultimately, loss of control (Refs. 1-3). 
The interaction between the pilot and the vehicle can be classified into two categories. The first one, called pilot-induced oscillations (PIO), is a sustained or uncontrollable unintentional oscillation resulting from the efforts of the pilot to control the aircraft (Ref. 4). Although the name puts all the blame on pilots, the fault for the phenomenon does not lie with pilots themselves. Pilots can exacerbate the situation since they are driven by the oscillation. Generally, a PIO results from a deficient flight control system or vehicle response. Moreover, according to Ref. 4, a PIO can be identified when the airplane attitude, angular rate, normal acceleration, or other quantity derived from these states, is approximately $180 \mathrm{deg}$ out of phase with the pilot's control inputs. Since the human operator's bandwidth is inherently limited, interactions of this nature take place at low frequency, specifically affecting the flight mechanics modes or system dynamics below $1 \mathrm{~Hz}$ (see Ref. 5).

The second category, called pilot-assisted oscillations (PAO), is the result of the unintentional, involuntary application of controls caused by vibrations of the cockpit. In this case, the mechanism of the interaction is completely different from that of PIOs, because vibrations are usually at frequencies above those of the human operator's bandwidth, generally between $2 \mathrm{~Hz}$ and $8 \mathrm{~Hz}$ (Ref. 5). During PAO events, the pilot interacts with the higher frequency aeroelastic modes of the vehicle.

PIO and PAO have been widely investigated in relation with fixedwing aircraft (Refs. 6-10). Rotary-wing aircraft PIOs received some attention throughout the years (Refs. 11, 12). Recently, RPC awareness was reviewed for the design of modern and innovative rotorcraft of enhanced performances and maneuverability (Ref. 1). Research on PAO phenomena for rotorcraft is ongoing. A good overview of PAO instabilities encountered on several U.S. Navy rotorcraft is reported by Walden in Ref. 13. In Europe, Hamel and Ockier (Refs. 11, 12) reported some critical RPC problems encountered with the German Aerospace Center's (DLR) ATTHeS (Advanced Technologies Testing Helicopter System) system, a modified BO105 helicopter equipped with a full authority nonredundant fly-by-wire (FBW) control system for the main rotor and fly-by-light system for the tail rotor. Similarly, tiltrotor aircraft have been subject to PAO events starting from the development of the XV-15 technology demonstrator. The V-22 Osprey suffered from aeroservoelastic pilot-in-the-loop couplings, as described, for example, by Parham et al. in Ref. 14.

During activity performed under the umbrella of GARTEUR Helicopter Action Group HC AG-16 (Ref. 5), the collective bounce phenomenon was deeply investigated. It is a RPC phenomenon caused by vertical vibrations in the aircraft cockpit that are transmitted to the collective lever through the torso, the left arm and the hand of the pilot and fed back to the rotor through the collective pitch control. The key factor was identified as being caused by the phase margin reduction introduced by the main rotor coning mode in the collective pitch-heave loop transfer function (Ref. 15).

PAO occurrences on the longitudinal and lateral axes should be less critical, since changes in cyclic pitch control do not cause immediate horizontal force imbalance, but rather pitch/roll moments, which are usually filtered by the low-pass behavior of the main rotor in most conventional rotorcraft, especially articulated ones. However, Refs. 12, 13, 16, and 17 report that the lateral axis tends to be also critical for PAO especially when a stability augmentation system (SAS) or an automatic flight control system (AFCS) is included in the pilot-vehicle system (PVS). Examples of such PAO occurrences have been reported in the United States on the CH-46D/E Sea Knight, the SH-60B Seahawk, the CH-53E Super Stallion with external loads (see Ref. 13) and in Europe on the BO105 (Ref. 12) and the EC135 (Ref. 16) research helicopters of the German Aerospace Center. PAOs were determined as the result of uncommanded pilot inputs interacting with the first vertical and lateral fuselage bending modes through the AFCS.

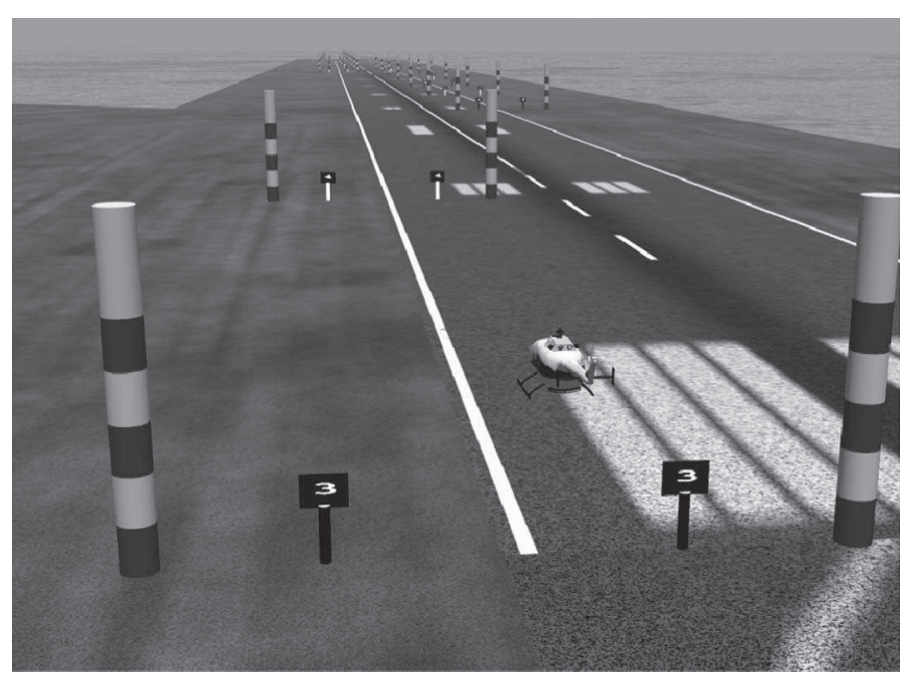

(a) Course layout for the roll step maneuver
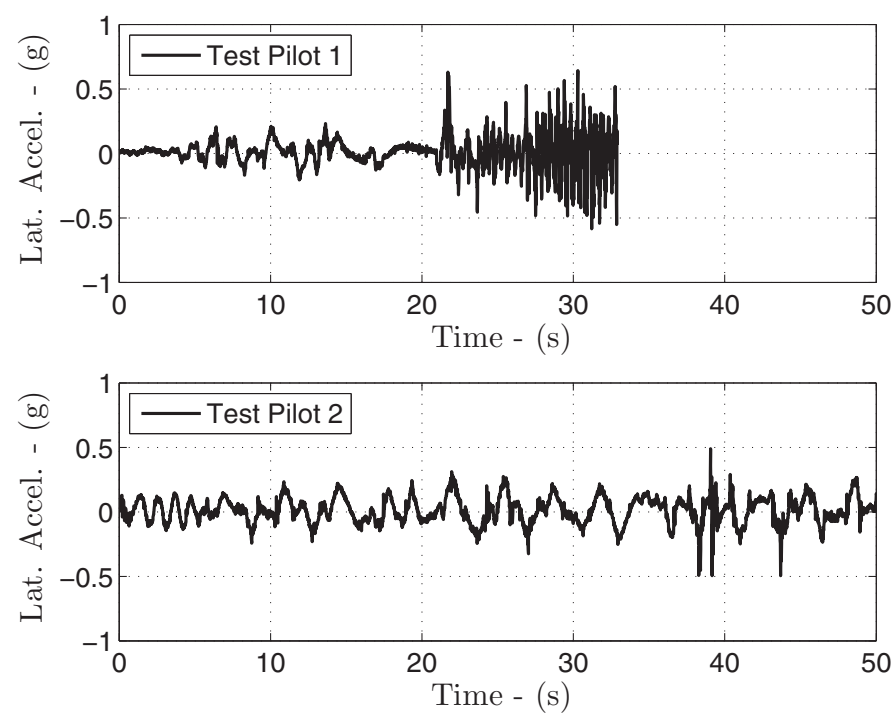

(b) Lateral acceleration measured at the pilot's seat

Fig. 1. Roll step maneuver (from Ref. 19).

The interaction between the pilot biodynamics and the vehicle dynamics are often amplified by the SAS/AFCS especially on the roll/lateral axis. However, artificial stability is necessary on helicopters since rotary wing aircraft are generally less stable than conventional fixed wing ones. Usually, phugoid and Dutch roll modes are intrinsically unstable in hover and low flight speed. A SAS/AFCS is often needed to reduce the pilot workload. The research performed in ARISTOTEL project (20102013) on RPC phenomena (Refs. 1,2) identified also PAO occurrences for the roll axis dynamics involving pilot biodynamics (Refs. 18, 19). Figure 1(a) presents a visual scene of the roll step maneuver performed in the simulator. The maneuver, developed at the University of Liverpool for tiltrotor handling qualities evaluation and subsequently adapted to helicopters (Ref. 20), is a modification of the slalom maneuver defined in Aircraft Design Standards (ADS) 33 (Ref. 21). It is designed to check both the vehicle's ability to maneuver in forward flight and the coordination required to perform the task. In the roll step maneuver, the pilot is flying as follows: From hover position along one edge of the runway, the pilot accelerates and flies through a series of gates traversing the runway from one side to the other in a specified distance. The roll step maneuver performed in ARISTOTEL was flown by two test pilots in a BO105-type 
helicopter. Test pilot \#1 triggered a PAO instability (see Fig. 1(b)) in the roll axis when flying at $80 \mathrm{kt}$ initial condition. Reference 22 showed that this instability was a result of an aeromechanical instability created by the lightly damped main rotor regressive lead-lag mode at $2.26 \mathrm{~Hz}$ coupled to the pilot biodynamics/lateral control inceptor dynamics. While pilot \#1 was not able to complete the roll step task, the biodynamics of pilot \#2 were not excited. The dependency of the outcome of the maneuver on the biodynamics of the test pilots calls for further investigation. Consequently, this work is developed to look for answers to questions such as: What is the PAO mechanism of roll axis fed back through pilot biodynamics? What is the simplest mathematical model able to capture this phenomenon? Why is this instability triggered only in some cases and not in others?

The paper proceeds as follows: The first section describes the roll/lateral PAO phenomenon and suggests a simple closed-loop model able to capture the PAO instability. Since the basic mechanism is quite similar to the well-known air resonance (AR), in which the airframe roll mode is coupled with the regressive cyclic flap and lead-lag rotor modes, a development of the six-degree-of-freedom (DOF) AR analytical model of Gandhi and Chopra (Ref. 23) is proposed. Its comparison with a detailed aeroservoelastic (ASE) helicopter model is presented to show that the main dynamics are well captured. The PVS is built by adding the pilot's biomechanics and a simple AFCS in feedback loop to the six-DOF AR model. Results of the PVS are discussed using two complementary techniques: the robust stability analysis and the force phasing matrices (FPM) approach. The first technique is used to exploit the robust stability of the PVS with respect to the AFCS parameters variation, which are considered uncertainty variables. The second one is used to reveal what are the most relevant DOF and which are interacting when the instability arises. The last section brings the paper to closure by drawing conclusions about the work performed.

\section{Problem Description}

This paper investigates the basic mechanism of aeroservoelastic PAO about the roll axis due to the interaction between vehicle roll motion and pilot's right arm biomechanics.

The motivation stems from the observation that a rotor imbalance may occur as a consequence of the excitation of the cyclic lead-lag modes. Such imbalance could excite the airframe rotation about the roll axis, causing in turn a lateral acceleration of the cockpit. The pilot could thus induce involuntary lateral deflection of the cyclic control inceptor, resulting in a potentially adverse closure of the control loop about the roll axis. This instability mechanism is analogous to the AR. AR is typical of helicopters with hingeless or bearingless rotors. Hingeless or bearingless main rotor designs compared to articulated main rotors are capable of building up large hub moments, which enhance the maneuverability and the aircraft response to pilot inputs. Generally, these vehicles are not prone to ground resonance; thus, they seldom have lead-lag dampers, as the aerodynamic in-plane damping is sufficient to stabilize the leadlag motion. However, in some cases, the lightly damped first lead-lag regressive mode can interact with the flight mechanics modes (body roll and/or pitch), leading to an instability in air (see Refs. 24-26). Events where the pilot's involuntary control inputs were exciting the AR mode are described, for example, by Refs. 16,17, and 27. As exemplified in the Introduction, this instability was also observed experimentally during test campaigns performed in the flight simulator of the University of Liverpool (Refs. 18, 22).

To understand the phenomenon, a simple closed-loop numerical model able to represent the basic mechanism of pilot-vehicle interaction is developed by connecting (a) the pilot's biodynamics between the lateral acceleration of the pilot seat and the lateral control inceptor position; (b) a basic AFCS model, simplified as a gain-time delay block; and (c) a six-DOF analytical helicopter model, including the cyclic flap $\left(\beta_{1 C}\right.$ and $\left.\beta_{1 S}\right)$ and lead-lag $\left(\zeta_{1 C}\right.$ and $\left.\zeta_{1 S}\right)$ main rotor DOF, coupled with the pitch $\left(\alpha_{Y}\right)$ and roll $\left(\alpha_{X}\right)$ body motions.

The model is built for a helicopter that resembles the MesserschmittBölkow-Blohm (MBB, now Airbus Helicopters) BO105. This hingeless, soft in-plane rotor system entered service in 1970. At its time, such a rotor design was a pioneering innovation for helicopters.

To compare the results of the six-DOF AR model with a more detailed and validated model, a full-state aeroservoelastic model of the BO105 has been realized in MASST (Modern Aeroservoelastic State Space Tools), a tool developed at Politecnico di Milano for the aeroservoelastic and aeromechanical analysis of rotorcraft (Refs. 28,29). Comparing the two models, it was observed that the dynamics of interest, included in a bandwidth overlapping that of the pilot biomechanics, is generally well captured by the six-DOF analytical model. However, the six-DOF model overestimates the damping of the low-frequency lead-lag regressive mode. It has been shown in Ref. 30 that the static residualization of the blade cyclic pitch dynamics is sufficient to recover the correct lead-lag damping.

A gain-time delay block is a rough approximation of a real AFCS. However, in a preliminary design phase, when the AFCS architecture has not been yet defined, it can well represent the uncertainty operator. The gain and the time delay have a direct impact on the gain and phase margins of the closed-loop system. Using the robust approach (Ref. 31), it is possible to define the stability boundaries for the AFCS design, to avoid roll/lateral PAO proneness.

Regarding pilot biodynamics, this work uses the results of several biodynamic feedthrough (BDFT) tests that have been conducted in the HELIFLIGHT flight simulator of the University of Liverpool, during the ARISTOTEL project test campaign performed in July 2012 (Refs. 18,22). The pilot's biodynamic transfer function (TF) of lateral cyclic with input lateral acceleration was identified with the structure:

$$
\frac{\delta_{Y}}{a_{Y}^{\text {seat }}}=H_{P P}(s)=-\mu_{P} \frac{s T_{z}+1}{s T_{p}+1} \frac{1}{\left(\frac{s}{\omega_{n}}\right)^{2}+2 \xi \frac{s}{\omega_{n}}+1}
$$

where $a_{Y}^{\text {seat }}$ is the acceleration measured in $g\left(1 g=9.81 \mathrm{~m} / \mathrm{s}^{2}\right)$ and $\delta_{Y}$ is the rotation of the cyclic control inceptor measured in percentage with a range of $\pm 100 \%$. The model of Eq. (1) is consistent with models proposed in the open literature (Refs. 32-35); the pilot transfer functions are similar to the ones measured in-flight and reported in Ref. 14. This model is a simplification of the classical "precision model" developed by McRuer et al. (Ref. 36), focused on high-frequency dynamics. It represents the classical neuromuscular dynamics through two complex-conjugate poles in Eq. (1) $\left(p_{1 / 2}=-\xi \omega_{n} \pm \mathrm{j} \omega_{n} \sqrt{1-\xi^{2}}\right)$. They are usually well damped ( $25 \%$ or more) and lie in the $2-3 \mathrm{~Hz}$ range. The real, low-frequency pole $\left(p_{3}=-1 / T_{p}\right)$ represents the integral contribution of the pilot's voluntary action. The zero, $z=-1 / T_{z}$ - usually at high frequencyrestores the correct asymptotic behavior of the transfer function. Data for the three pilots considered in this work are shown in Table 1. It is worth noticing that the static gain $\mu_{P}$ of the transfer function of pilot \#1 is significantly higher than that of the other pilots. The differences in the results obtained for pilot \#1 are probably related to their anthropometric characteristics: Pilot \#1 belongs to the 99th percentile in terms of height and weight, showing somewhat different biomechanical properties from those of an average individual.

It is also worth remarking that, since the pilot dynamics are highly nonlinear, a database of pilot's BDFT should be identified for the same pilot flying different mission tasks. However, this is an ambitious and expensive target. Generally, for tasks of increasing complexity pilots tend 
Table 1. Pilot/lateral stick dynamic properties

\begin{tabular}{lrrrc}
\hline \hline & Pilot \#1 & Pilot \#2 & Pilot \#3 & Units \\
\hline$\mu_{P}$ & 216.26 & 88.67 & 83.88 & $\% / g$ \\
$T_{Z}$ & 0.02 & 0.05 & 0.03 & $\mathrm{~s}$ \\
$T_{p}$ & 0.51 & 0.49 & 0.26 & $\mathrm{~s}$ \\
$\xi$ & 26.87 & 23.11 & 39.66 & $\%$ \\
$\omega_{n}$ & 14.12 & 19.05 & 16.14 & $\mathrm{rad} / \mathrm{s}$ \\
\hline \hline
\end{tabular}

to be more concentrated and reactive, enhancing their neuromuscular tension. During the experimental tests for the identification of the pilot's BDFT described in Ref. 22, the pilot's only task was to try to maintain the stick in its nominal initial position, simulating a hover precision task. However, with the same pilot's BDFT it was predicted, and reproduced at the flight simulator of the University of Liverpool, the roll/lateral PAO instability occurred with test pilot \#1, during the roll step task at $80 \mathrm{kt}$.

Finally, a research group from Politecnico di Milano is currently working at a detailed multibody model of the pilot upper limbs (Refs. 37-39). The pilot's BDFT can be estimated from the multibody model, considering pilots with different anthropometric characteristics that perform different tasks. This approach promises to be much faster and cheaper than the experimental identification of the pilot's BDFT.

\section{Helicopter Model}

The RPC phenomena on the roll axis experienced in ARISTOTEL's project experimental campaign presented several similarities with AR. Numerical predictions of roll/lateral PAO instabilities performed on helicopters with hingeless or bearingless main rotor show that the vicinity of pilot's biodynamic poles to main rotor lightly damped first regressive lead-lag mode may lead to a reduction of the phase margin of the PVS (Ref. 22). The phenomenon involves the modal participation of the main rotor cyclic flap and lead-lag modes, and the fuselage rigid roll and pitch modes, as for AR, which interact with pilot's biodynamics.

The mechanism through which the lateral PAO instability evolves is sketched in Fig. 2. The cycle starts when a lateral cyclic pitch control is introduced by the pilot into the control chain. Both cosine and sine cyclic dynamics must be taken into account when using multiblade coordinates, since cyclic terms are strongly coupled. The blades pitch dynamics modifies the angle of attack of each blade, inducing a flapping motion which in turn changes the tip path plane of the main rotor, generating pitch and roll moments. The aerodynamic forces are mainly responsible for

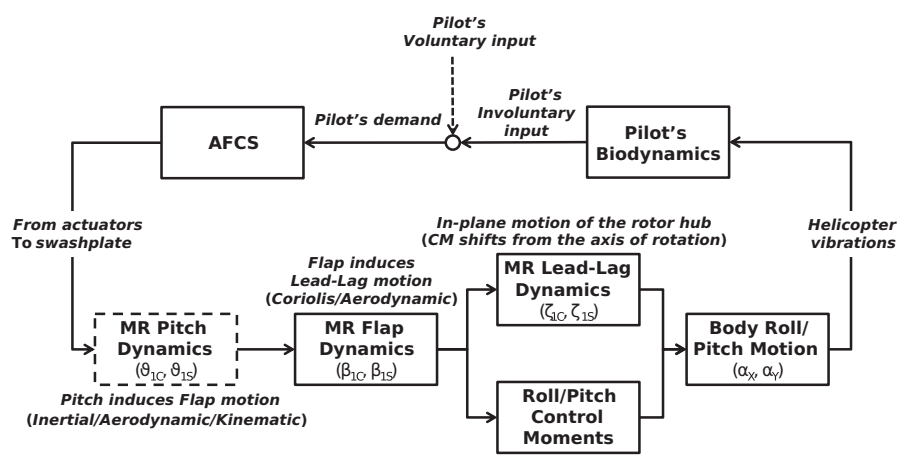

Fig. 2. The lateral PAO mechanism of instability. the couplings between the pitch and the flap dynamics. The Coriolis terms cause couplings between the flap and the lead-lag motions and between the rotor and body motions. A secondary-but nonnegligiblecontribution is due to the aerodynamic coupling of the lead-lag with the flapping motion. In turn, the cyclic lead-lag modes $\zeta_{1 C}$ and $\zeta_{1 S}$ cause an in-plane shift of the rotor center of mass from the axis of rotation, producing vibratory roll and pitch moments, and lateral and longitudinal vibrations that are transmitted from the rotor hub to the pilot seat.

\section{Analytical model}

The starting point to build an analytical model for roll/lateral RPC is the models originally developed to investigate AR, like the one presented in Ref. 23. These models consider six DOF: the two cyclic flap $\left(\beta_{1 C}, \beta_{1 S}\right)$, the two cyclic lead-lag $\left(\zeta_{1 C}, \zeta_{1 S}\right)$, and the two airframe roll and pitch $\left(\alpha_{X}\right.$, $\alpha_{Y}$ ) ones, which are included in the independent coordinate vector $\mathbf{q}$. The lateral and longitudinal displacements are assumed to have only a minor effect (Ref. 24) and are thus neglected. The aeromechanical system in second-order form is

$$
\begin{aligned}
\mathbf{M}(\mathbf{p}) \mathbf{q}^{\prime \prime}+\mathbf{C}(\mathbf{p}) \mathbf{q}^{\prime}+\mathbf{K}(\mathbf{p}) \mathbf{q} & =\mathbf{B}(\mathbf{p}) \mathbf{u}, \\
y & =R \Omega^{2} \mathbf{D} \mathbf{q}^{\prime \prime}
\end{aligned}
$$

where matrices $\mathbf{M}, \mathbf{C}$, and $\mathbf{K}$ include both the structural and aerodynamic contributions, which are functions of the trim parameters $\mathbf{p}$. The superscript ()$^{\prime}$ denotes the derivative with respect to the azimuthal coordinate $\psi=\Omega t$. The control vector $\mathbf{u}$ contains the lateral and longitudinal cyclic pitch angles, namely $\mathbf{u}=\left\{\vartheta_{1 C} ; \vartheta_{1 S}\right\}$. The output $y$ is the lateral acceleration measured at the pilot's seat, $y=a_{Y}^{\text {seat }}$. For a rigid fuselage model, it can be expressed as a linear combination of the second derivative of the independent coordinate vector elements, from Eq. (2a). The terms of the matrices can be found in Refs. 23 and 24 .

The linearized helicopter dynamics can be expressed in the Laplace domain to obtain an algebraic relation between the two inputs and the single output, namely

$$
y(s)=s^{2} R \Omega^{2} \mathbf{D}\left(\mathbf{M}(\mathbf{p}) s^{2}+\mathbf{C}(\mathbf{p}) s+\mathbf{K}(\mathbf{p})\right)^{-1} \mathbf{B}(\mathbf{p}) \mathbf{u}(s)
$$

The resulting equation is the combination of two transfer functions

$$
a_{Y}^{\text {seat }}=H_{Y C}(s, \mathbf{p}) \vartheta_{1 C}+H_{Y S}(s, \mathbf{p}) \vartheta_{1 S}
$$

that represent, respectively, the transfer function between the lateral cyclic and the lateral acceleration at the pilot seat, and the transfer function between the longitudinal cyclic and the same lateral acceleration.

The lightly damped low-frequency vibrations caused by the lead-lag regressive mode can interact with the pilot's biomechanic poles in the lateral direction, which are in the $2-3 \mathrm{~Hz}$ range, creating a feedback path through involuntary lateral cyclic control inputs to the main rotor dynamics.

Usually, an instability may arise in this loop when an AFCS is included in the PVS. In particular, the introduction of a gain and a time delay between the control inceptor motion and the swashplate servoactuators may reduce the PVS gain and phase margins.

\section{Detailed model}

A comparison of the above-described six-DOF analytical model with the BO105 aeroservoelastic model used in the ARISTOTEL's project flight simulator test campaign was performed. This was done to check whether the analytic model is adequate to represent the basic elements required to predict the instability phenomenon. The full BO105 aeroelastic model was validated against flight-test data as presented in Ref. 22. 
The aeroservoelastic BO105 was built using MASST. All models obtained in MASST are linear time invariant (LTI), computed using coefficient averaging to eliminate any periodicity whenever the rotors are not in axial flow conditions. The airframe structural model is represented by the six rigid body modes. The rotor has been modeled considering three bending modes, two torsion modes, and the three state Pitt-Peters dynamic inflow model (Ref. 40). The tail rotor is modeled as a rigid teetering rotor; coning and teetering modes have been considered for the two-blade teetering rotor. Typical linear servoactuator transfer functions are defined for the three actuators of the main rotor swashplate and for the single actuator of the tail rotor. The model includes sensors for positions, velocities, and accelerations at the pilot seat in the longitudinal, lateral, and vertical directions and three sensors for measuring the roll, pitch, and yaw angular rates $p, q, r$. Finally, the airframe stability derivatives, resulting from the contribution of the fuselage/wing body, the horizontal tail, and the vertical tail have been estimated using the aerodynamic coefficients lookup tables provided in Ref. 41, to take into account the low-frequency flight dynamics behavior. The general characteristics of the aircraft were taken from Refs. 5 and 41.

\section{Model verification and validation}

The LTI MASST model of the BO105 is characterized by 62 states. The root locus in hover, Sea Level Standard (SLS) International Standard Atmosphere (ISA) $+0^{\circ}$ condition is shown in Fig. 3(a) up to $110 \mathrm{rad} / \mathrm{s}$; Fig. 3(b) presents a detail of the low-frequency roots. The eigenvalues are compared with those obtained from the six-DOF AR analytical model.

The full-state MASST model is able to represent the low-frequency eigenvalues associated with the modes that are relevant for flight mechanics (see Fig. 3(b), bottom). Dutch roll, phugoid, heave subsidence, and spiral modes show the trends reported in Chapter 4 of Ref. 41. Longperiod pitching oscillations, related to phugoid dynamics, are unstable. The effect of the dynamic inflow model is significant on the flap/rigid body modes, which are associated with the longitudinal and lateral dynamics of the rotor tip path plane coupled with the body angular rates. Flap roots are well damped, whereas, owing to the absence of leadlag dampers, the lead-lag regressive and progressive poles are located quite close to the imaginary axis, as shown in Fig. 3. As a result of the blade flexbeam stiffness, the regressive lead-lag root shows a small natural frequency compared with helicopters of the same class featuring an articulated main rotor.

The eigenanalysis of the six-DOF AR analytical model returns two real and four complex-conjugate poles. The eigenvalues are shown in Fig. 3 and reported in Table 2, with the corresponding mode shapes. The open-loop system is stable, since all roots have negative real parts. Pitch and roll subsidence roots, related to the helicopter stability derivatives $M_{/ q}$ and $L_{/ p}$, are well captured (Ref. 41).

Several differences can be noticed in Fig. 3 between the two models. The full-state MASST flap progressive mode is quite close to the

Table 2. Eigenvalues of six-DOF AR model - hover, SLS

\begin{tabular}{lccc}
\hline \hline Mode & $\begin{array}{c}\text { Eigenvalue } \\
(\mathrm{rad} / \mathrm{s})\end{array}$ & $\begin{array}{c}\text { Frequency } \\
(\mathrm{Hz})\end{array}$ & $\begin{array}{c}\text { Damping } \\
(\%)\end{array}$ \\
\hline Pitch subsidence & -4.292 & - & - \\
Roll subsidence & -10.806 & - & - \\
Flap regressive & $-7.870 \pm \mathrm{j} 8.159$ & 1.298 & 69.42 \\
Lag regressive & $-0.595 \pm \mathrm{j} 13.924$ & 2.216 & 4.27 \\
Lag progressive & $-1.103 \pm \mathrm{j} 77.317$ & 12.305 & 1.43 \\
Flap progressive & $-14.609 \pm \mathrm{j} 91.216$ & 14.517 & 15.81 \\
\hline \hline
\end{tabular}

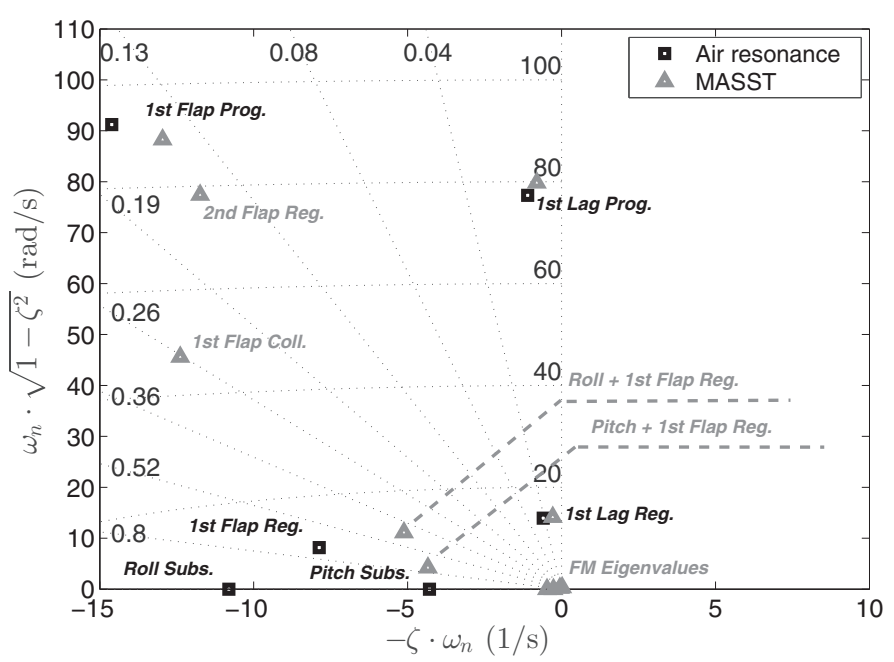

(a) Overall stability map
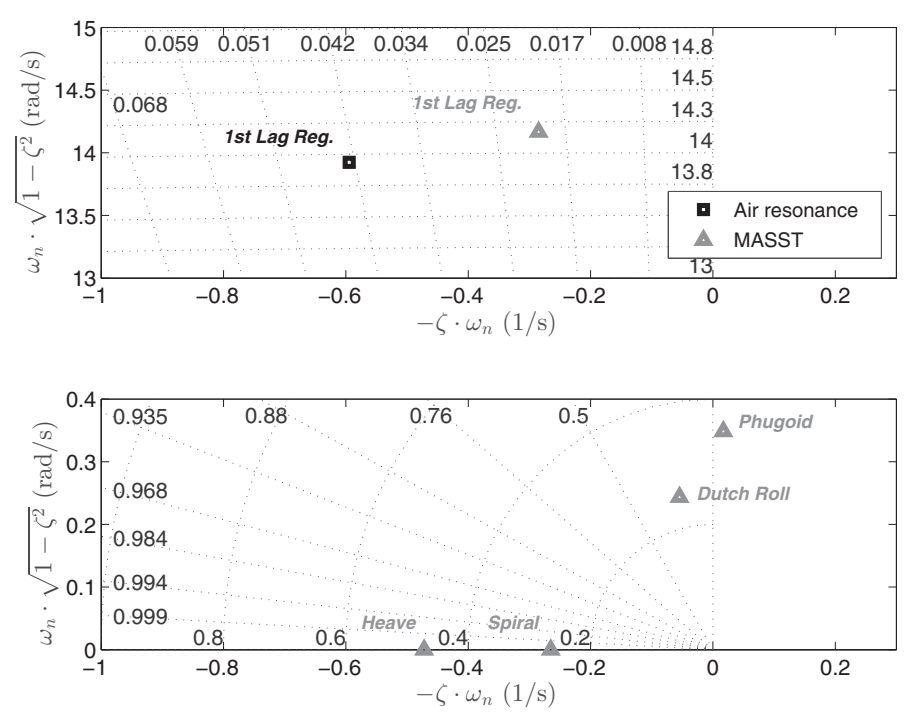

(b) Zoom: First lag reg. (top); detail of FM roots (bottom)

Fig. 3. Eigenvalues: six-DOF AR model vs. MASST model.

corresponding mode computed by the six-DOF AR model, although less damped. The difference is caused by the absence of inflow dynamics in the AR model.

The lead-lag regressive and progressive frequencies are well correlated between the two models, but the MASST lead-lag roots are less damped. In particular, the damping reduction on the regressive root is more than $50 \%$ in the full-state MASST model (4.27\% of the AR model vs. $2.01 \%$ of the MASST one; Fig. 3(b)). Finally, in the full-state MASST model the low frequency flap regressive mode is coupled with the pitch and the roll subsidence modes, generating two complex-conjugate roots. These effects are related to the interaction between the pitch and roll airframe dynamics and the inflow lateral and longitudinal dynamics, which reduce the aerodynamic loads during the transients and the modal damping of the flap dynamics. The two dynamical models were thoroughly compared in Ref. 30, where it was shown that (a) the effects of the rigid fuselage lateral mode and of the servoactuator second-order dynamics (with a cutoff frequency of about $10 \mathrm{~Hz}$ ) reduce the phase angle of the MASST TF between the lateral cyclic pitch control and the lateral seat acceleration in the bandwidth between 2.5 and $10 \mathrm{~Hz}$. At 
Table 3. Eigenvalues of six-DOF AR model with residualized pitch dynamics: hover, SLS

\begin{tabular}{lccc}
\hline \hline Mode & $\begin{array}{c}\text { Eigenvalue } \\
(\mathrm{rad} / \mathrm{s})\end{array}$ & $\begin{array}{c}\text { Frequency } \\
(\mathrm{Hz})\end{array}$ & $\begin{array}{c}\text { Damping } \\
(\%)\end{array}$ \\
\hline Pitch subsidence & -3.276 & - & - \\
Roll subsidence & -11.224 & - & - \\
Flap regressive & $-8.516 \pm \mathrm{j} 8.214$ & 1.307 & 71.97 \\
Lag regressive & $-0.307 \pm \mathrm{j} 13.970$ & 2.223 & 2.19 \\
Lag progressive & $-0.928 \pm \mathrm{j} 77.509$ & 12.336 & 1.20 \\
Flap progressive & $-14.542 \pm \mathrm{j} 88.213$ & 14.039 & 16.26 \\
\hline \hline
\end{tabular}

frequencies above $10 \mathrm{~Hz}$, the lead-lag progressive peak can be noticed, respectively, at $12.3 \mathrm{~Hz}$ in the six-DOF AR model and $12.7 \mathrm{~Hz}$ in the full-state MASST model; (b) the inflow dynamics has a negligible effect in the $2-8 \mathrm{~Hz}$ frequency range.

In conclusion, the six-DOF AR analytical model gives a reasonable representation of the essential PVS dynamics in the bandwidth of interest related to PAO phenomena, although there are important shortcomings. In particular, the analytical model overestimates the damping of the regressive lead-lag mode, unless the static residualized effect of the blade cyclic pitch dynamics is included. These dynamics are usually characterized by higher frequencies when compared with the first flap or lead-lag dynamics and thus they are usually neglected. However, the static torsional compliance contribution spilled out on the low-frequencies main rotor dynamics is essential to capture the correct lead-lag damping , as reported in Ref. 30. The importance of the torsional static compliance has been already highlighted for other RPC phenomena (e.g., collective bounce) in Refs. 42 and 43, where it was shown that both the main rotor control chain compliance and the blade torsional elasticity required a lower pilot's gain to reach the verge of stability. Conversely, the same analyses performed with a rigid control chain and torsionally rigid blades were characterized by higher stability margins. Again the contribution of the torsional compliance was static since the first blade torsion mode was one decade higher than the unstable mode.

The eigenvalues obtained with the updated six-DOF AR model, which includes the static residualization of the blade pitch dynamics, are reported in Table 3. The lead-lag regressive damping decreases from 4.27\% of the original six-DOF AR model (Table 2) to $2.19 \%$ for the six-DOF AR model with residualized pitch dynamics, reaching a value closer to the $2.01 \%$ of the full state MASST model.

The effect of the lightly damped lead-lag regressive mode can be also observed in Fig. 4, where the Bode plot of the TF between $\vartheta_{1 C}$ and $a_{Y}^{\text {seat }}$ is shown. The TF obtained with the six-DOF AR analytical model including the static residualization of the blade pitch dynamics clearly shows a more pronounced peak at the regressive lead-lag frequency. This model can be considered adequate for preliminary studies of roll/lateral PAO phenomena, since it is able to reproduce the roll/lateral PAO instability described in Ref. 22. The analytical model reveals the relevant DOF of the instability and allows for investigating of the fundamental cause of leadlag regressive mode destabilization by the pilot. The next paragraphs will look for a deeper understanding of the physical mechanism of lead-lag instability involving pilot biodynamics. In this sense, two approaches will be used: (1) robust stability analysis and (2) energetic analysis of the system in the so-called FPM approach.

\section{Robust Stability Analysis for Understanding Lead-Lag Instability through Pilot Biodynamics}

Instead of using the classical eigenvalues investigation, the robust stability analysis approach can be exploited. This approach gives infor-
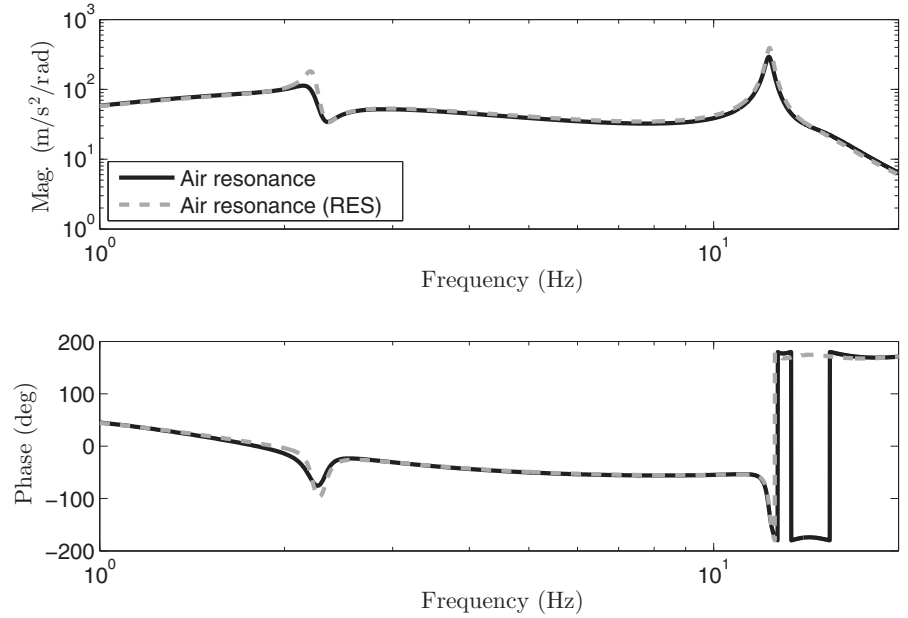

Fig. 4. Bode plot of $H_{Y C}$ : original AR model vs. updated AR model with residualized (RES) blade pitch dynamics.

mation about the grade of stability with respect to parameter variations (Refs. 31,44,45). Hence, stability analysis is performed using complexvariable transfer functions and exploiting the generalized Nyquist criterion (Ref. 46), which, in the present case, can be formulated as (see, e.g., Ref. 47 for a proof)

Given a single input-single output (SISO) dynamic system $H(s)$ and an uncertainty operator $K(s)=G_{Y} e^{-s \tau_{Y}}$ (where $G_{Y}$ and $\tau_{Y}$ are real numbers, with $G_{Y}$ positive) that are in feedback loop, the system is marginally stable whenever the frequency response of the loop transfer function (LTF) $P(\mathrm{j} \omega)=H(\mathrm{j} \omega) K(\mathrm{j} \omega)$ crosses the critical point in the complex plane $(-1+\mathrm{j} 0)$.

In the case at hand, the nominal LTF can be easily obtained by directly feeding the pilot/lateral control inceptor dynamic model (1) into the vehicle model:

$$
H_{\mathrm{nom}}(s, \mathbf{p})=-G_{1 C} H_{P P}(s) H_{Y C}(s, \mathbf{p})
$$

where $G_{1 C}$ is the gearing ratio between the lateral control inceptor displacement and the rotor lateral cyclic pitch; for the BO105 model used in the flight simulator was $G_{1 C}=-0.05 \mathrm{deg} / \%$. The minus sign in Eq. (5) is introduced because the pilot contribution provides a negative feedback loop closure.

The uncertainty operator represents a possible variation of gain or time delay that may be introduced in the control loop by the simplified AFCS model used here. Consequently, the stability boundary can be found analytically by solving for $\hat{G}_{Y}(\omega)$ and $\hat{\tau}_{Y}(\omega)$ the complex-variable equation

$$
\hat{G}_{Y} e^{-\mathrm{j} \omega \hat{\tau}_{Y}} H_{\text {nom }}(\mathrm{j} \omega, \mathbf{p})=-1
$$

for all frequencies $\omega \in[-\infty,+\infty]$. This means that

$$
\begin{aligned}
\hat{G}_{Y} & =\left|\frac{1}{H_{\mathrm{nom}}(\mathrm{j} \omega, \mathbf{p})}\right| \\
\theta(\omega) & =\tan ^{-1}\left(\hat{\tau}_{Y} \omega\right)=-\frac{\operatorname{Im}\left(H_{\mathrm{nom}}(\mathrm{j} \omega, \mathbf{p})\right)}{\operatorname{Re}\left(H_{\mathrm{nom}}(\mathrm{j} \omega, \mathbf{p})\right)}
\end{aligned}
$$

Thus Bode plots of $H_{\text {nom }}(\mathrm{j} \omega)$ can be used to evaluate $\hat{G}_{Y}(\omega)$ and $\hat{\tau}_{Y}(\omega)$.

The Nyquist plot of the detailed BO105 MASST model connected to the model of pilot $\# 1$ at a gain of $G_{Y} \geq 2.5$ and for a time 


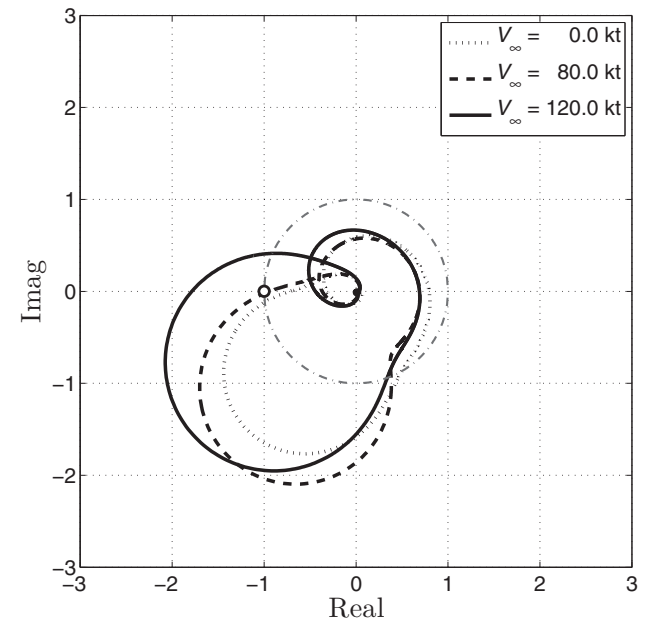

Fig. 5. Nyquist plot of the LTF: $G_{Y}=2.5$; $\tau_{Y}=140 \mathrm{~ms}$; test pilot \#1, SLS. MASST model.

delay of $140 \mathrm{~ms}$ (obtained by adding a delay of $100 \mathrm{~ms}$ the one that is intrinsic of the flight simulator filters and hardware time delay, which is about $40 \mathrm{~ms}$ ), is shown in Fig. 5 for several flight velocities. At $80 \mathrm{kt}$, the model predicts a marginally stable system; the experiments from ARISTOTEL described in the Introduction (see Fig. 1) indeed found an incipient PAO instability. Consequently, it can be stated that the numerical model reasonably predicts the stability of the PVS (see Ref. 22).

In addition, Fig. 5 shows that increasing the flight speed increases the proneness of roll/lateral PAO to instability. This trend has been obtained for all the test pilots. Robust stability margins decrease when increasing the flight speed, since higher accelerations are perceived by the pilots due to the higher control moments generated by the main rotor (Ref. 22). However, such proneness is also present in the Nyquist plot in hover conditions. Looking at pilot \#1 characteristics as described in Table 1, it appears that this pilot showed a quicker behavior with a high-gain representative of a more reactive piloting, since the associated structural gain, $\mu_{P}$, is approximately 2.5 times higher than that of pilots \#2 and \#3. A higher gain pilot destabilizes the lead-lag mode (Ref. 22). As the task workload increases with increasing helicopter velocity, the pilot will tend to increase their neuromuscular activation, driving the lead-lag mode unstable (Ref. 48).

\section{Robust stability analysis: Numerical results}

Robust stability analyses have been carried out for the combination of two values of gain $G_{Y}$ and time delay $\tau_{Y}$ : nominal, $G_{Y}$ increased up to a factor 3.0 and a time delay up to $140 \mathrm{~ms}$, in hover SLS ISA $+0^{\circ}$ flight conditions. The robust approach has been applied to the six-DOF AR analytical model with residualized blade pitch dynamics, in feedback loop with the identified pilot's BDFT of Eq. (1) and the basic AFCS. For instability to occur, the gain must increase such that the LTF exceeds $0 \mathrm{~dB}$ and the time delay must increase to a point that phase margin is depleted. The high-gain increase ensures that a $0 \mathrm{~dB}$ crossover frequency is present. The combination of high gain and time delay then decreases the phase margin to the point of instability. Generally, the introduction of a time delay in piloted flight simulation increases the workload of the pilot, especially when performing a precision task involving the roll axis. An increase in time delay alone beyond $100 \mathrm{~ms}$ has been reported in Ref. 49 to reduce the handling qualities of the BO105 about the roll axis from level 1 to level 2. Thus it represents a candidate for the trigger of $\mathrm{PIO}$ and PAO events. It is worth noticing that, in the presence of excessive

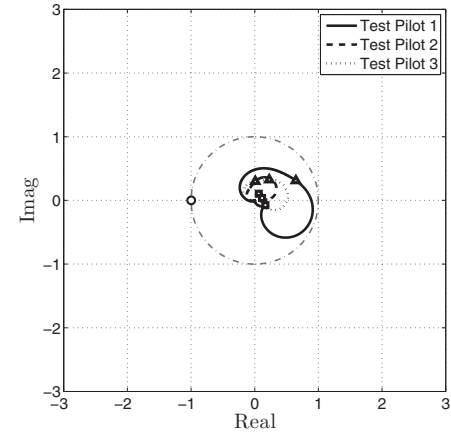

(a) $G_{Y}=1.0, \tau_{Y}=0.0 \mathrm{~ms}$

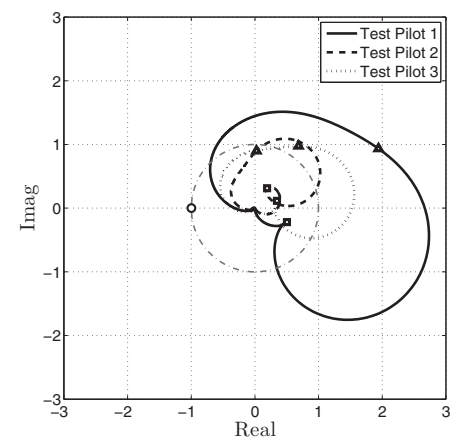

(c) $G_{Y}=3.0, \tau_{Y}=0.0 \mathrm{~ms}$

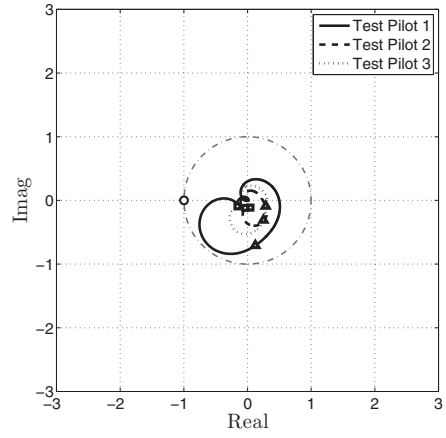

(b) $G_{Y}=1.0, \tau_{Y}=140.0 \mathrm{~ms}$

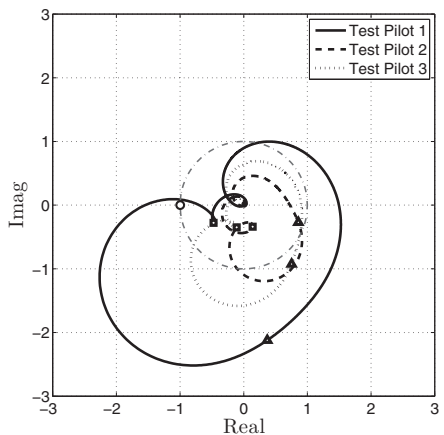

(d) $G_{Y}=3.0, \tau_{Y}=140.0 \mathrm{~ms}$

Fig. 6. Nyquist plots of the LTF, hover SLS. Six-DOF AR model with residualized blade pitch dynamics.

delay, many pilots may chose to back out of the loop and thereby reduce their workload because the delay prevents tight control. In these cases, it would become difficult to complete the task or to comply with adequate performances. In the proposed work it is assumed that the pilot is focused to complete a precision task, where a continuous control of the vehicle by the pilot is requested.

Time delays in the control system of actual aircraft can be introduced by FBW systems, specifically by the digital acquisition and filtering of control device motion and by signal processing before feeding inputs to the actuators. Delays of the order of $80 \mathrm{~ms}$ are plausible, but higher values have been reported, especially in early experimental aircraft (see, e.g., the discussion in Ref. 1).

The Nyquist plot of the configuration with nominal gain and no time delay, Fig. 6(a), remains inside the circle of unit radius. The corresponding closed-loop system is characterized by robust stability margins. The lightly damped lead-lag regressive mode of the main rotor produces an enlargement of the LTF's lobe between $2.1 \mathrm{~Hz}$ (indicated with $\triangle$ ) and $2.5 \mathrm{~Hz}$ (indicated with $\square$ ). The differences between the three test pilots are clearly visible. Test pilot \#1 is characterized by a larger lobe caused by a static gain of the pilot's biodynamic TF $\left(\mu_{P}=216.26 \% / g\right.$; Table 1$)$ higher than that of the other pilots. Moreover, the LTF of test pilot \#1 is the most shifted toward point $(-1+\mathrm{j} 0)$ in the Argand plane (see Fig. 6) compared with that of the other two test pilots.

The configuration characterized by a larger lateral gearing ratio $\left(G_{Y}=3.0\right)$ and no time delay is shown in Fig. 6(c). The increase in gain alone is not sufficient to cause the locus of any of the LTF curves to circumvent the point $(-1+\mathrm{j} 0)$.

The time delay produces a clockwise rotation of the Nyquist curves. The effect of the time delay alone does not destabilize the PVS (see Fig. 6(b)) although the Nyquist curves become closer to the critical point $(-1+j 0)$ in the frequency region of the main rotor regressive lead-lag mode. 


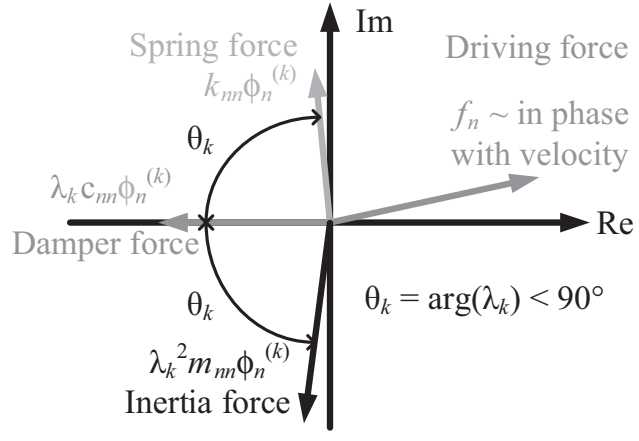

Fig. 7. Driving forces in complex plane.

Finally, the combination of an increased gearing ratio and time delay drives test pilot \#1 to the PAO condition (Fig. 6(d)). Test pilots \#2 and $\# 3$ are not predicted to jeopardize the stability of the coupled system as severely as pilot \#1. The LTFs for pilots \#2 and \#3 also result in a reduced phase margin, which would make the system unstable with an additional 50-100 ms of time delay. However, time delays higher than $140 \mathrm{~ms}$ were considered unrealistic by the pilots, as the workload would have become intolerable and vehicle-handling qualities would have deteriorated too much.
It should be noted that the PAO predicted for the $\mathrm{BO} 105$ is related to the loss of stability margin of the lateral acceleration/cyclic pitch control LTF caused by the spillover of the lightly damped regressive lead-lag mode (see also Ref. 30).

In conclusion, with a gain $G_{Y}$ increased to 3.0 and a time delay $\tau_{Y}$ of $140 \mathrm{~ms}$, the six-DOF AR model coupled with the pilot's biodynamics produces a PAO instability in hover. This result is slightly more conservative, compared with the numerical predictions obtained with pilot \#1 flying the full-state ASE BO105 in hover (Ref. 22), where the same values of gain and time delay returned a marginally stable PVS. However, it is posited that the proposed model can be used to predict the roll/lateral PAO proneness on hingeless/bearingless helicopters during an early design stage, since it is able to capture the roll/lateral PAO phenomenon. Moreover, with a simple, parametric, model of the helicopter dynamics, it is possible to investigate the PAO instability mechanism and the DOF that activate it, as shown in the next section.

\section{Force Phasing Matrices Analysis for Understanding Lead-Lag Instability through Pilot Biodynamics}

Identifying the path of these energy flows for a given instability gives a complementary point of view to the previous analysis and can help the system designer to mitigate it. The energy flows can be found

FPM - Mass

$\begin{array}{rcccccccccc} & \text { beta1c } & \text { beta1s } & \text { zeta1c } & \text { zeta1s } & \text { alphax } & \text { alphay } & \mathrm{V} & \text { deltay } & \text { thetalc } \\ \text { beta1c } & 1.28 \mathrm{E}-02 & -1.26 \mathrm{E}-03 & -9.97 \mathrm{E}-02 & 9.11 \mathrm{E}-03 & -9.97 \mathrm{E}-03 & 2.05 \mathrm{E}-01 & 0.00 \mathrm{E}+00 & 0.00 \mathrm{E}+00 & 0.00 \mathrm{E}+00 & \text { lag/flap } \\ \text { beta1s } & -5.93 \mathrm{E}-04 & 1.28 \mathrm{E}-02 & 3.33 \mathrm{E}-03 & -2.10 \mathrm{E}-01 & 2.56 \mathrm{E}-01 & 3.08 \mathrm{E}-03 & 0.00 \mathrm{E}+00 & 0.00 \mathrm{E}+00 & 0.00 \mathrm{E}+00 & \text { lag/flap } \\ \text { zeta1c } & 2.79 \mathrm{E}-03 & 1.62 \mathrm{E}-04 & 1.48 \mathrm{E}-01 & -1.82 \mathrm{E}-03 & -3.31 \mathrm{E}-01 & 3.08 \mathrm{E}-03 & 0.00 \mathrm{E}+00 & 0.00 \mathrm{E}+00 & 0.00 \mathrm{E}+00 \\ \text { zeta1s } & 2.10 \mathrm{E}-04 & 1.13 \mathrm{E}-02 & -1.79 \mathrm{E}-03 & 1.48 \mathrm{E}-01 & 4.46 \mathrm{E}-03 & -1.39 \mathrm{E}-01 & 0.00 \mathrm{E}+00 & 0.00 \mathrm{E}+00 & 0.00 \mathrm{E}+00 \\ \text { alphax } & 1.34 \mathrm{E}-03 & -7.95 \mathrm{E}-01 & 7.51 \mathrm{E}-01 & -2.84 \mathrm{E}-01 & 5.92 \mathrm{E}-02 & -1.40 \mathrm{E}-02 & 0.00 \mathrm{E}+00 & 0.00 \mathrm{E}+00 & 0.00 \mathrm{E}+00 \\ \text { alphay } & -9.72 \mathrm{E}-01 & -3.70 \mathrm{E}-03 & -6.24 \mathrm{E}-01 & 1.03 \mathrm{E}+00 & 1.18 \mathrm{E}-01 & 1.68 \mathrm{E}-01 & 0.00 \mathrm{E}+00 & 0.00 \mathrm{E}+00 & 0.00 \mathrm{E}+00 \\ \text { v } & 0.00 \mathrm{E}+00 & 0.00 \mathrm{E}+00 & 0.00 \mathrm{E}+00 & 0.00 \mathrm{E}+00 & 9.97 \mathrm{E}-01 & 0.00 \mathrm{E}+00 & 7.10 \mathrm{E}-06 & 0.00 \mathrm{E}+00 & 0.00 \mathrm{E}+00 \\ \text { deltay } & 0.00 \mathrm{E}+00 & 0.00 \mathrm{E}+00 & 0.00 \mathrm{E}+00 & 0.00 \mathrm{E}+00 & 0.00 \mathrm{E}+00 & 0.00 \mathrm{E}+00 & 0.00 \mathrm{E}+00 & 4.77 \mathrm{E}-02 & 0.00 \mathrm{E}+00 \\ \text { theta1c } & 0.00 \mathrm{E}+00 & 0.00 \mathrm{E}+00 & 0.00 \mathrm{E}+00 & 0.00 \mathrm{E}+00 & 0.00 \mathrm{E}+00 & 0.00 \mathrm{E}+00 & 0.00 \mathrm{E}+00 & -9.45 \mathrm{E}-05 & 6.04 \mathrm{E}-05\end{array}$

FPM - Damping

\begin{tabular}{|c|c|c|c|c|c|c|c|c|c|c|}
\hline & beta1c & beta1s & zetalc & zeta1s & alphax & alphay & $\mathrm{v}$ & deltay & theta1c & \\
\hline seta1c & $-1.00 \mathrm{E}+00$ & $-3.15 \mathrm{E}+00$ & 4.85E-01 & $6.99 \mathrm{E}-01$ & $-2.20 \mathrm{E}+00$ & $1.32 \mathrm{E}-01$ & $0.00 \mathrm{E}+00$ & $0.00 \mathrm{E}+00$ & $0.00 \mathrm{E}+00$ & lag/flap \\
\hline betals & $1.41 \mathrm{E}+00$ & $-1.00 \mathrm{E}+00$ & $1.30 \mathrm{E}+00$ & $1.71 \mathrm{E}-01$ & $-1.37 \mathrm{E}-01$ & $-8.29 \mathrm{E}-01$ & $0.00 \mathrm{E}+00$ & $0.00 \mathrm{E}+00$ & $0.00 \mathrm{E}+00$ & lag/flap \\
\hline zetalc & $2.64 \mathrm{E}-01$ & $-6.84 \mathrm{E}-02$ & $-1.00 \mathrm{E}+00$ & $3.48 \mathrm{E}-01$ & $2.31 \mathrm{E}-02$ & $-7.09 \mathrm{E}-02$ & $0.00 \mathrm{E}+00$ & $0.00 \mathrm{E}+00$ & $0.00 \mathrm{E}+00$ & roll/lag \\
\hline zeta1s & $-1.62 \mathrm{E}-02$ & $2.04 \mathrm{E}-01$ & $-3.42 \mathrm{E}-01$ & $-1.00 \mathrm{E}+00$ & $-1.73 \mathrm{E}-01$ & $1.53 \mathrm{E}-02$ & $0.00 \mathrm{E}+00$ & $0.00 \mathrm{E}+00$ & $0.00 \mathrm{E}+00$ & \\
\hline lphax & $2.99 \mathrm{E}+00$ & $-3.71 \mathrm{E}-01$ & $1.83 \mathrm{E}+00$ & $-3.62 \mathrm{E}-01$ & $-1.00 \mathrm{E}+00$ & $4.24 \mathrm{E}-01$ & $0.00 \mathrm{E}+00$ & $0.00 \mathrm{E}+00$ & $0.00 \mathrm{E}+00$ & \\
\hline phay & 5.33E-01 & $8.30 \mathrm{E}+00$ & $-4.85 \mathrm{E}-01$ & $4.07 \mathrm{E}+00$ & $-1.41 \mathrm{E}+00$ & $-1.00 \mathrm{E}+00$ & $0.00 \mathrm{E}+00$ & $0.00 \mathrm{E}+00$ & $0.00 \mathrm{E}+00$ & \\
\hline $\mathrm{v}$ & $0.00 \mathrm{E}+00$ & $0.00 \mathrm{E}+00$ & $0.00 \mathrm{E}+00$ & $0.00 \mathrm{E}+00$ & $0.00 \mathrm{E}+00$ & $0.00 \mathrm{E}+00$ & $-1.00 \mathrm{E}+00$ & $0.00 \mathrm{E}+00$ & $0.00 \mathrm{E}+00$ & \\
\hline Itay & $0.00 \mathrm{E}+00$ & $0.00 \mathrm{E}+00$ & $0.00 \mathrm{E}+00$ & $0.00 \mathrm{E}+00$ & $0.00 \mathrm{E}+00$ & $0.00 \mathrm{E}+00$ & $4.95 \mathrm{E}-02$ & $-1.00 \mathrm{E}+00$ & $0.00 \mathrm{E}+00$ & \\
\hline talc & $0.00 \mathrm{E}+00$ & $0.00 \mathrm{E}+00$ & $0.00 \mathrm{E}+00$ & $0.00 \mathrm{E}+00$ & $0.00 \mathrm{E}+00$ & $0.00 \mathrm{E}+00$ & $0.00 \mathrm{E}+00$ & $-1.00 \mathrm{E}+00$ & $-1.00 \mathrm{E}+00$ & \\
\hline
\end{tabular}

\begin{tabular}{|c|c|c|c|c|c|c|c|c|c|c|}
\hline \multirow{2}{*}{\multicolumn{11}{|c|}{ PM - Stiffness }} \\
\hline & betalc & beta $1 \mathrm{~s}$ & zetalc & zetals & alphax & alphay & $\mathrm{v}$ & deltay & thetalc & \\
\hline beta1c & $1.06 \mathrm{E}-02$ & $3.56 \mathrm{E}+00$ & $-1.13 E+00$ & $-1.59 \mathrm{E}+00$ & $0.00 \mathrm{E}+00$ & $0.00 \mathrm{E}+00$ & $0.00 \mathrm{E}+00$ & $0.00 \mathrm{E}+00$ & $4.07 \mathrm{E}+00$ & pilot to flap \\
\hline beta1s & $1.52 \mathrm{E}+00$ & $1.06 \mathrm{E}-02$ & $-5.41 \mathrm{E}-01$ & $-2.07 \mathrm{E}+00$ & $0.00 \mathrm{E}+00$ & $0.00 \mathrm{E}+00$ & $0.00 \mathrm{E}+00$ & $0.00 \mathrm{E}+00$ & $9.54 \mathrm{E}-02$ & \\
\hline zetalc & $-4.14 \mathrm{E}-02$ & $-6.84 \mathrm{E}-01$ & $-7.76 \mathrm{E}-01$ & $3.14 \mathrm{E}+00$ & $0.00 \mathrm{E}+00$ & $0.00 \mathrm{E}+00$ & $0.00 \mathrm{E}+00$ & $0.00 \mathrm{E}+00$ & $-9.60 \mathrm{E}-01$ & \\
\hline zeta1s & $-8.24 \mathrm{E}-01$ & $-1.91 \mathrm{E}-01$ & $3.09 \mathrm{E}+00$ & $-7.76 \mathrm{E}-01$ & $0.00 \mathrm{E}+00$ & $0.00 \mathrm{E}+00$ & $0.00 \mathrm{E}+00$ & $0.00 \mathrm{E}+00$ & $-1.14 \mathrm{E}-02$ & \\
\hline alphax & $-1.78 \mathrm{E}+00$ & $-1.27 \mathrm{E}+00$ & $2.64 \mathrm{E}+00$ & $-2.93 \mathrm{E}+00$ & $0.00 \mathrm{E}+00$ & $0.00 \mathrm{E}+00$ & $0.00 \mathrm{E}+00$ & $0.00 \mathrm{E}+00$ & $1.11 \mathrm{E}-01$ & \\
\hline alphay & $-1.52 \mathrm{E}+00$ & $4.06 \mathrm{E}+00$ & $-6.58 \mathrm{E}+00$ & $3.74 \mathrm{E}+00$ & $0.00 \mathrm{E}+00$ & $0.00 \mathrm{E}+00$ & $0.00 \mathrm{E}+00$ & $0.00 \mathrm{E}+00$ & $-9.43 E+00$ & \\
\hline $\mathrm{v}$ & $0.00 \mathrm{E}+00$ & $0.00 \mathrm{E}+00$ & $0.00 \mathrm{E}+00$ & $0.00 \mathrm{E}+00$ & $0.00 \mathrm{E}+00$ & $0.00 \mathrm{E}+00$ & $3.46 \mathrm{E}-03$ & $0.00 \mathrm{E}+00$ & $0.00 \mathrm{E}+00$ & \\
\hline deltay & $0.00 \mathrm{E}+00$ & $0.00 \mathrm{E}+00$ & $0.00 \mathrm{E}+00$ & $0.00 \mathrm{E}+00$ & $0.00 \mathrm{E}+00$ & $0.00 \mathrm{E}+00$ & $8.56 \mathrm{E}-01$ & $4.64 \mathrm{E}-02$ & $0.00 \mathrm{E}+00$ & \\
\hline thetalc & $0.00 \mathrm{E}+00$ & $0.00 \mathrm{E}+00$ & $0.00 \mathrm{E}+00$ & $0.00 \mathrm{E}+00$ & $0.00 \mathrm{E}+00$ & $0.00 \mathrm{E}+00$ & $0.00 \mathrm{E}+00$ & $-1.53 \mathrm{E}+00$ & $3.53 \mathrm{E}+00$ & \\
\hline
\end{tabular}

Fig. 8. Numerical values of the FPMs for $G_{Y}=3.0$ and $\tau_{Y}=0 \mathrm{~ms}$. 
by using the FPM approach as proposed in Ref. 50. The FPM technique consists in identifying which DOF mutually pump energy into each other around an unstable equilibrium of a system. The presence of an unstable mode in a linear system means that at least one of the system's states amplitude will grow exponentially if perturbed from equilibrium. In order for its amplitude to grow exponentially, one can intuitively understand that some power is increasingly being exchanged by the given DOF with a source. To identify the energy flows, the first step consists in finding the driving forces. These forces are defined as the ones that are in phase with a given DOF velocity. In an autonomous linear system casted into the conventional mass $\mathbf{M}(\mathbf{p})$, damping $\mathbf{C}(\mathbf{p})$, and stiffness $\mathbf{K}$ (p) matrices, each line of the system of equations is the formalization of an equilibrium of forces and moments. By computing the eigenvalues, $\lambda_{k}$, and the eigenvectors, $\boldsymbol{\phi}^{(\mathbf{k})}$, of the system, each DOF can be expressed through an eigenbasis, namely,

$$
\mathbf{q}=\sum q_{0}^{(k)} \cdot e^{\lambda_{k} t} \cdot \boldsymbol{\phi}^{(\mathbf{k})}
$$

where a set of arbitrary multiplying coefficients, $q_{0}^{(k)}$, is also included in Eq. (8) to satisfy an arbitrary initial condition. By only expressing the component of the preceding equation with respect to the $k$ th eigenvector, the $n$th line of the system of equations separated into terms based on their position (diagonal or nondiagonal) and nature (mass, damping, stiffness) would be

$$
\begin{aligned}
m_{n n} \lambda_{k}^{2} \phi_{n}^{(k)} & +c_{n n} \lambda_{k} \phi_{n}^{(k)}+k_{n n} \phi_{n}^{(k)} \\
& +\underbrace{\sum_{j \neq n}\left(m_{n j} \lambda_{k}^{2}+c_{n j} \lambda_{k}+k_{n j}\right) \phi_{j}^{(k)}}_{f_{n}}=0
\end{aligned}
$$

The first three terms can be called inertia, damping, and elastic forces, whereas $f_{n}$ can be interpreted as an excitation force of the $n$th DOF. Since the eigenvalues are usually complex numbers, one could see the four terms of Eqs. (9) as a sum of vectors in the complex plane that result in the null vector. If we suppose the $k$ th mode to be unstable, then the real part of $\lambda_{k}$ is positive. If we only look at the eigenvalue with a positive imaginary part (for the sake of simplicity and without loss of generality), then its argument $\theta_{k}$ is between 0 and $90 \mathrm{deg}$. By finding a transformation such that the damper force equals unity and is aligned with the real axis in the negative direction, one would obtain Fig. 7. The forces with positive real part have a component in phase with the velocity of the given DOF; as such, they are defined as driving forces. Such a transformation is given by the FPM (Ref. 50),

$$
\begin{aligned}
& \mathbf{P}_{M}^{(k)}=\left[p_{M_{i j}}^{(k)}\right]=-\Re\left[\left[m_{i j}\right] \times\left[\frac{\alpha_{j}^{(k)}}{\beta_{i}^{(k)} \cdot c_{i i}}\right]\right] \\
& \mathbf{P}_{C}^{(k)}=\left[p_{C_{i j}}^{(k)}\right]=-\Re\left[\left[c_{i j}\right] \times\left[\frac{\beta_{j}^{(k)}}{\beta_{i}^{(k)} \cdot c_{i i}}\right]\right] \\
& \mathbf{P}_{K}^{(k)}=\left[p_{K_{i j}}^{(k)}\right]=-\Re\left[\left[k_{i j}\right] \times\left[\frac{\gamma_{j}^{(k)}}{\beta_{i}^{(k)} \cdot c_{i i}}\right]\right]
\end{aligned}
$$

where the product is a term by term product and $\alpha, \beta$ and $\gamma$ are defined such as

$$
\begin{aligned}
\left\{\alpha^{(k)}\right\} & =\lambda_{k}^{2}\left\{\phi^{(k)}\right\} \\
\left\{\beta^{(k)}\right\} & =\lambda_{k}\left\{\phi^{(k)}\right\} \\
\left\{\gamma^{(k)}\right\} & =\left\{\phi^{(k)}\right\}
\end{aligned}
$$

Driving forces are in practice the extradiagonal terms of the FPMs (see the example of Fig. 8). At each line, only the largest (biggest contributors) driving forces that mutually pump energy into corresponding DOFs are

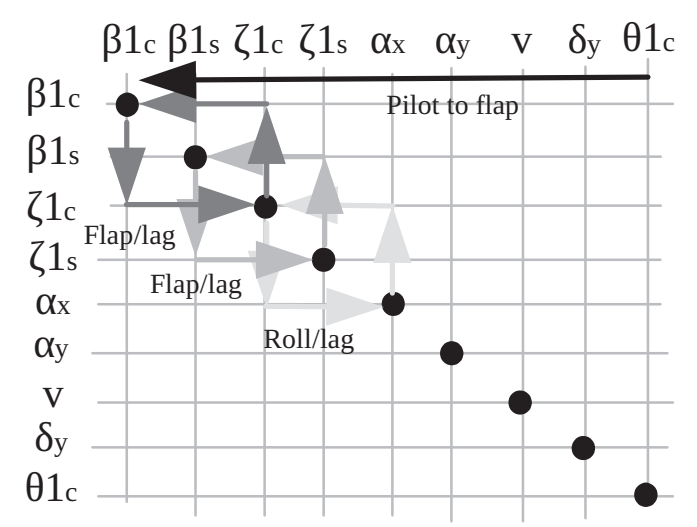

Fig. 9. No instability, energy flows for $G_{Y}=3.0$ and $\tau_{Y}=0 \mathrm{~ms}$.

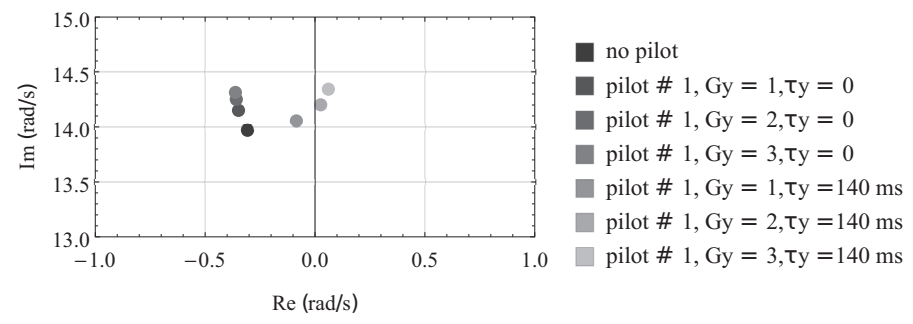

Fig. 10. Lead-lag regressing mode eigenvalue for varying $G_{Y}$ and $\tau_{Y}$.

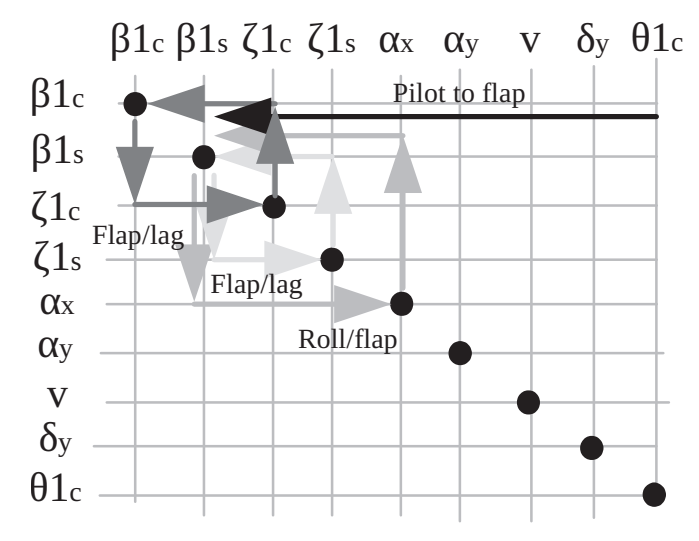

Fig. 11. Instability, energy flows for $G_{Y}=3.0$ and $\tau_{Y}=140 \mathrm{~ms}$.

highlighted. To mutually pump energy into each other, a large positive real term in a phasing matrix needs to have a symmetric positive term with respect to the diagonal of the matrix. The arrows of Fig. 8 point the driving force to the respective excited DOF. For example, if we take the first line of the first numerical FPM in Fig. 8, only one extradiagonal term can be highlighted: It is positive, and, symmetrically to the diagonal, another positive term is found. As a result, $\zeta_{1 s}$ is pumping energy into $\beta_{1 c}$ and reciprocally. Once this is done for the three matrices, a more visual simplified (in terms of relevant DOFs) and qualitative way of looking at the results is presented in Fig. 9. In this figure, each color represents an energy loop of DOFs that mutually pump energy into each other. Looking for the position of the original terms in the mass, damping and stiffness matrices gives the analytical expressions of the critical forces.

A first step in the application of FPM interpretation in the present case first requires one to recast the system's equations. In the problem 
FPM - Mass

\begin{tabular}{|c|c|c|c|c|c|c|c|c|c|c|}
\hline & betalc & beta1s & zetalc & zetals & alphax & alphay & $\mathrm{v}$ & deltay & thetalc & \\
\hline $1 \mathrm{c}$ & $-2.15 \mathrm{E}-03$ & $-2.95 \mathrm{E}-0$ & $-9.47 \mathrm{E}-02$ & $8.02 \mathrm{E}-03$ & $-3.19 \mathrm{E}-02$ & $1.52 \mathrm{E}-01$ & $0.00 \mathrm{E}+00$ & $0.00 \mathrm{E}+00$ & $0.00 \mathrm{E}+00$ & g/flap \\
\hline & $-3.16 \mathrm{E}-04$ & $-2.15 \mathrm{E}-03$ & $1.69 \mathrm{E}-03$ & $-8.53 \mathrm{E}-02$ & $1.20 \mathrm{E}-01$ & $-5.31 \mathrm{E}-05$ & $0.00 \mathrm{E}+00$ & $0.00 \mathrm{E}+00$ & $0.00 \mathrm{E}+00$ & cap \\
\hline zeta1c & $2.83 \mathrm{E}-03$ & $4.89 \mathrm{E}-04$ & $-2.49 \mathrm{E}-02$ & $-1.84 \mathrm{E}-03$ & $-7.92 \mathrm{E}-01$ & $2.26 \mathrm{E}-03$ & $0.00 \mathrm{E}+00$ & $0.00 \mathrm{E}+00$ & $0.00 \mathrm{E}+00$ & \\
\hline & 2.38 & $2.34 \mathrm{E}$ & $-1.78 \mathrm{E}-03$ & -2. & $-3.62 \mathrm{E}-03$ & $-1.92 \mathrm{E}-01$ & $0.00 \mathrm{E}+00$ & $0.00 \mathrm{E}+00$ & $0.00 \mathrm{E}+00$ & \\
\hline lphax & $1.78 \mathrm{E}-03$ & $-5.94 \mathrm{E}-01$ & $5.54 \mathrm{E}-01$ & 6.73 & $-9.96 \mathrm{E}-03$ & $-4.56 \mathrm{E}-03$ & $0.00 \mathrm{E}+00$ & $0.00 \mathrm{E}+00$ & $0.00 \mathrm{E}+00$ & \\
\hline & $-9.33 \mathrm{E}-01$ & 4.73E-04 & $-4.47 \mathrm{E}-01$ & $1.61 \mathrm{E}+00$ & $1.36 \mathrm{E}-01$ & $-2.83 \mathrm{E}-02$ & $0.00 \mathrm{E}+00$ & $0.00 \mathrm{E}+00$ & $0.00 \mathrm{E}+00$ & \\
\hline $\mathrm{v}$ & $0.00 \mathrm{E}+00$ & $0.00 \mathrm{E}+00$ & $0.00 \mathrm{E}+00$ & $0.00 \mathrm{E}+00$ & $1.00 \mathrm{E}+00$ & $0.00 \mathrm{E}+00$ & $-1.19 \mathrm{E}-06$ & $0.00 \mathrm{E}+00$ & $0.00 \mathrm{E}+00$ & \\
\hline ltay & $0.00 \mathrm{E}+00$ & $0.00 \mathrm{E}+00$ & $0.00 \mathrm{E}+00$ & $0.00 \mathrm{E}+00$ & $0.00 \mathrm{E}+00$ & $0.00 \mathrm{E}+00$ & $0.00 \mathrm{E}+00$ & $-8.03 \mathrm{E}-03$ & $0.00 \mathrm{E}+00$ & \\
\hline eta $1 \mathrm{c}$ & $0.00 \mathrm{E}+00$ & $0.00 \mathrm{E}+00$ & $0.00 \mathrm{E}+00$ & $0.00 \mathrm{E}+00$ & $0.00 \mathrm{E}+00$ & $0.00 \mathrm{E}+00$ & $0.00 \mathrm{E}+00$ & $-3.11 \mathrm{E}-01$ & $-1.42 \mathrm{E}-03$ & \\
\hline
\end{tabular}

FPM - Damping
$\begin{array}{rcccccccccc}\text { beta1c } & \text { beta1s } & \text { zeta1c } & \text { zeta1s } & \text { alphax } & \text { alphay } & \text { v } & \text { deltay } & \text { theta1c } \\ \text { beta1c } & -1.00 \mathrm{E}+00 & -5.42 \mathrm{E}+00 & 4.28 \mathrm{E}-01 & 6.30 \mathrm{E}-01 & -5.71 \mathrm{E}-02 & 2.51 \mathrm{E}-01 & 0.00 \mathrm{E}+00 & 0.00 \mathrm{E}+00 & 0.00 \mathrm{E}+00 & \text { lag/flap } \\ \text { beta1s } & 5.82 \mathrm{E}-01 & -1.00 \mathrm{E}+00 & 5.08 \mathrm{E}-01 & 9.09 \mathrm{E}-02 & 3.90 \mathrm{E}-01 & -3.96 \mathrm{E}-01 & 0.00 \mathrm{E}+00 & 0.00 \mathrm{E}+00 & 0.00 \mathrm{E}+00 & \text { lag/flap } \\ \text { zeta1c } & 3.01 \mathrm{E}-01 & -1.44 \mathrm{E}-01 & -1.00 \mathrm{E}+00 & 8.02 \mathrm{E}-01 & -1.72 \mathrm{E}-02 & -1.03 \mathrm{E}-01 & 0.00 \mathrm{E}+00 & 0.00 \mathrm{E}+00 & 0.00 \mathrm{E}+00 \\ \text { zeta1s } & -1.85 \mathrm{E}-02 & 5.72 \mathrm{E}-01 & -7.73 \mathrm{E}-01 & -1.00 \mathrm{E}+00 & -4.11 \mathrm{E}-01 & 1.06 \mathrm{E}-02 & 0.00 \mathrm{E}+00 & 0.00 \mathrm{E}+00 & 0.00 \mathrm{E}+00 \\ \text { alphax } & 2.95 \mathrm{E}-02 & 1.68 \mathrm{E}+00 & -4.00 \mathrm{E}-01 & -2.59 \mathrm{E}-01 & -1.00 \mathrm{E}+00 & 7.82 \mathrm{E}-01 & 0.00 \mathrm{E}+00 & 0.00 \mathrm{E}+00 & 0.00 \mathrm{E}+00 & \text { roll/flap } \\ \text { alphay } & 1.33 \mathrm{E}+00 & 2.18 \mathrm{E}+01 & -7.16 \mathrm{E}-01 & 2.94 \mathrm{E}+00 & -8.97 \mathrm{E}+00 & -1.00 \mathrm{E}+00 & 0.00 \mathrm{E}+00 & 0.00 \mathrm{E}+00 & 0.00 \mathrm{E}+00 & \\ \text { v } & 0.00 \mathrm{E}+00 & 0.00 \mathrm{E}+00 & 0.00 \mathrm{E}+00 & 0.00 \mathrm{E}+00 & 0.00 \mathrm{E}+00 & 0.00 \mathrm{E}+00 & -1.00 \mathrm{E}+00 & 0.00 \mathrm{E}+00 & 0.00 \mathrm{E}+00 & \\ \text { deltay } & 0.00 \mathrm{E}+00 & 0.00 \mathrm{E}+00 & 0.00 \mathrm{E}+00 & 0.00 \mathrm{E}+00 & 0.00 \mathrm{E}+00 & 0.00 \mathrm{E}+00 & 6.27 \mathrm{E}-02 & -1.00 \mathrm{E}+00 & 0.00 \mathrm{E}+00 & \\ \text { theta1c } & 0.00 \mathrm{E}+00 & 0.00 \mathrm{E}+00 & 0.00 \mathrm{E}+00 & 0.00 \mathrm{E}+00 & 0.00 \mathrm{E}+00 & 0.00 \mathrm{E}+00 & 0.00 \mathrm{E}+00 & 3.95 \mathrm{E}-01 & -1.00 \mathrm{E}+00\end{array}$

FPM - Stiffness

$\begin{array}{rcccccccccc}\text { beta1c } & \text { beta1s } & \text { zeta1c } & \text { zeta1s } & \text { alphax } & \text { alphay } & \mathrm{v} & \begin{array}{c}\text { deltay } \\ \text { theta1c }\end{array} \\ \text { beta1c }-1.78 \mathrm{E}-03 & 7.87 \mathrm{E}+00 & -8.80 \mathrm{E}-01 & -1.42 \mathrm{E}+00 & 0.00 \mathrm{E}+00 & 0.00 \mathrm{E}+00 & 0.00 \mathrm{E}+00 & 0.00 \mathrm{E}+00 & -4.36 \mathrm{E}-01 \\ \text { beta1s } & 8.51 \mathrm{E}-01 & -1.78 \mathrm{E}-03 & -3.02 \mathrm{E}-01 & -8.11 \mathrm{E}-01 & 0.00 \mathrm{E}+00 & 0.00 \mathrm{E}+00 & 0.00 \mathrm{E}+00 & 0.00 \mathrm{E}+00 & 5.34 \mathrm{E}-02 \\ \text { pilot to flap } \\ \text { zeta1c }-5.06 \mathrm{E}-02 & -1.86 \mathrm{E}+00 & 1.30 \mathrm{E}-01 & 3.17 \mathrm{E}+00 & 0.00 \mathrm{E}+00 & 0.00 \mathrm{E}+00 & 0.00 \mathrm{E}+00 & 0.00 \mathrm{E}+00 & -4.13 \mathrm{E}-01 \\ \text { zeta1s }-9.16 \mathrm{E}-01 & -4.09 \mathrm{E}-01 & 3.05 \mathrm{E}+00 & 1.30 \mathrm{E}-01 & 0.00 \mathrm{E}+00 & 0.00 \mathrm{E}+00 & 0.00 \mathrm{E}+00 & 0.00 \mathrm{E}+00 & -4.25 \mathrm{E}-02 \\ \text { alphax }-2.15 \mathrm{E}+00 & -9.50 \mathrm{E}-01 & 1.86 \mathrm{E}+00 & 7.11 \mathrm{E}-01 & 0.00 \mathrm{E}+00 & 0.00 \mathrm{E}+00 & 0.00 \mathrm{E}+00 & 0.00 \mathrm{E}+00 & -3.13 \mathrm{E}-01 \\ \text { alphay }-1.48 \mathrm{E}+00 & -3.83 \mathrm{E}-01 & -4.91 \mathrm{E}+00 & 5.35 \mathrm{E}+00 & 0.00 \mathrm{E}+00 & 0.00 \mathrm{E}+00 & 0.00 \mathrm{E}+00 & 0.00 \mathrm{E}+00 & -1.43 \mathrm{E}+01 \\ \text { v } 0.00 \mathrm{E}+00 & 0.00 \mathrm{E}+00 & 0.00 \mathrm{E}+00 & 0.00 \mathrm{E}+00 & 0.00 \mathrm{E}+00 & 0.00 \mathrm{E}+00 & -5.80 \mathrm{E}-04 & 0.00 \mathrm{E}+00 & 0.00 \mathrm{E}+00 \\ \text { deltay } 0.00 \mathrm{E}+00 & 0.00 \mathrm{E}+00 & 0.00 \mathrm{E}+00 & 0.00 \mathrm{E}+00 & 0.00 \mathrm{E}+00 & 0.00 \mathrm{E}+00 & 9.53 \mathrm{E}-01 & -7.78 \mathrm{E}-03 & 0.00 \mathrm{E}+00 \\ \text { theta1c } 0.00 \mathrm{E}+00 & 0.00 \mathrm{E}+00 & 0.00 \mathrm{E}+00 & 0.00 \mathrm{E}+00 & 0.00 \mathrm{E}+00 & 0.00 \mathrm{E}+00 & 0.00 \mathrm{E}+00 & 9.22 \mathrm{E}-01 & -4.23 \mathrm{E}-03\end{array}$

Fig. 12. Numerical values of the FPMs for $G_{Y}=3.0$ and $\tau_{Y}=140 \mathrm{~ms}$.

at hand, the matrices $\mathbf{M}(\mathbf{p}), \mathbf{C}(\mathbf{p}), \mathbf{K}(\mathbf{p})$ as given by Eqs. (2) need to be extended with pilot biodynamics. For this purpose, the transfer functions representing pilot biodynamics (see Eq. (1)), lateral cyclic control gain, and time delay need to be transformed from the Laplace domain to time domain. It is proposed to add $v, \delta_{Y}$, and $\vartheta_{1 C}$ as state variables to the system's equations. The time delay is modeled by a Padé approximation of the second order. Considering a time delay of $140 \mathrm{~ms}$, the corresponding phase delay at the frequency of the unstable eigenvalue, i.e., about $2 \mathrm{~Hz}$, is about $100 \mathrm{deg}$. A second-order Padé approximation is relatively accurate in representing the phase delay up to $180 \mathrm{deg}$. As a consequence, its choice is deemed acceptable in the present case. The additional equations due to pilot and AFCS therefore become

$$
\begin{aligned}
\mu_{P} a_{Y}^{\text {seat }}+T_{p} \dot{v}+v & =0 \\
\frac{1}{\omega_{n}^{2}} \ddot{\delta}_{Y}+\frac{2 \xi}{\omega_{n}} \dot{\delta}_{Y}+\delta_{Y}-T_{z} \dot{v}-v & =0 \\
\vartheta_{1 C}+\frac{\tau_{Y}}{2} \dot{\vartheta}_{1 C}+\frac{\tau_{Y}^{2}}{12} \ddot{\vartheta}_{1 C}-G_{Y} G_{1 C}\left(\delta_{Y}-\frac{\tau_{Y}}{2} \dot{\delta}_{Y}+\frac{\tau_{Y}^{2}}{12} \ddot{\delta}_{Y}\right) & =0
\end{aligned}
$$

The addition of $\vartheta_{1 C}$ as a state variable to the equations of motion results in extra aerodynamic terms in $\mathbf{M}(\mathbf{p}), \mathbf{C}(\mathbf{p}), \mathbf{K}(\mathbf{p})$ matrices that can be directly obtained from the input matrix $\mathbf{B}(\mathbf{p})$ in Eq. (2a).

\section{Energy flows during instability: Numerical results}

As stated earlier, when both $G_{Y}$ and $\tau_{Y}$ are increased, the lead-lag regressive mode might become unstable (see Fig. 10).

To better understand the mechanism behind this potential instability, it is proposed to map the energy flows in two cases: the first for $G_{Y}=$ 3.0 and $\tau_{Y}=0 \mathrm{~ms}$, for which the absence of time delay leads to a stable system, and the second by increasing $\tau_{Y}$ to $140 \mathrm{~ms}$ to drive the system unstable. The computation of the FPMs leads to the results shown in Figs. 9 and 11, in which the main involved vicious energy circles can be identified.

In both cases, two main vicious energy circles involving flap/lag are present. However, a comparison between these figures shows that the time delay in the lateral cyclic controls modifies the way the body couples with rotor motion. In presence of small or no time delays, body roll couples 
with the rotor through the lead-lag DOF. The increase of the time delay to 140 ms modifies this coupling: The body no longer couples with the rotor through lead-lag but directly through flap motion (see Figs. 11 and 12). It is interesting to observe that the pilot biodynamics participate in the destabilization of the system by transferring energy into the flap DOF, rather than directly into the lead-lag DOF. Indeed, the direct effect of the pilot's input is on the pitch of the blade, which almost directly translates into flapping moment, causing the response of the flapping DOF. Flap motion produces roll motion through aerodynamic forces and lead-lag motion through Coriolis forces. If not damped enough, these motions become divergent. So, this is the mechanism of the regressive lag mode destabilization in the adverse roll axis instability via pilot biodynamical feedthrough coupling.

\section{Conclusions}

The analysis performed in this work leads to the conclusions discussed in the following.

1) The interaction between the pilot biodynamics and the vehicle dynamics about the roll/lateral axis appears to be critical, and may lead to PAO.

2) The combination of the AFCS gearing ratio and the time delay proves to be the critical factor for PAO susceptibility. An increased gearing ratio combined with a time delay in the order of $140 \mathrm{~ms}$ (obtained by adding a delay of $100 \mathrm{~ms}$ to the one that is intrinsic of the flight simulator filters and hardware, which is about $40 \mathrm{~ms}$ ) applied to the vehicle model in flight at $80 \mathrm{kt}$ was shown to represent a marginally stable system and proved to drive a test pilot into the PAO condition during piloted flight simulation experiments.

3) The six-DOF AR model, characterized by a selected number of parameters, is able to capture the PAO phenomenon in which the poorly damped lead-lag regressive mode becomes unstable when coupled with the pilot's biodynamics. So, it can be used to predict instabilities during an early design stage of the helicopter.

4) Using an energetic approach to understand the basic mechanism through which regressive lead-lag mode induces aeroservoelastic PAO about the roll axis, this work showed that the pilot biodynamics is feeding the system destabilization by inputting energy into the flap DOF. Flap motion becomes roll motion through aerodynamic forces, and lead-lag motion through Coriolis forces. Roll body motion, in turn, couples with the rotor through the flap DOF. Unless sufficiently damped, these motions become divergent. This is the mechanism of the regressive lead-lag mode destabilization in the adverse roll axis instability via pilot BDFT coupling. It is interesting to observe that, depending on the value of the time delay involved in the lateral cyclic control, the rotorcraft body couples with rotor motion in a different way. In the presence of small or no time delays, body roll couples with the rotor through the lag DOF. The increase of the time delay to 140ms modifies this coupling: the body no longer couples with the rotor through lag but directly through flap motion.

At this point, a final remark on the use of flight simulation for PAO investigation seems appropriate. Flight simulators are generally able to reproduce the dynamics of rotorcraft within a certain degree of fidelity. Consequently, PIO and PAO phenomena can be predicted by flight simulator test campaigns. However, it is worth noticing that whereas the vehicle dynamics are repeatable, the pilot's behavior might not be. In real flight, PIO (or PAO) events similar to those occurring in simulated flight can appear. However, not only intrinsic differences between the actual and the simulated vehicle, but also differences in the pilot's response to the different environments could mask existing, or even, on the contrary, expose non-existing PIO (or PAO) proneness. As a consequence, comparing simulated and real flight results is not an easy task. Nonetheless, flight simulator test campaigns aimed at PIO/PAO investigation are useful to highlight potential instability mechanisms that could otherwise go unnoticed until late into flight testing of aircraft.

\section{Acknowledgments}

Part of the research leading to these results has received funding from the European Community's Seventh Framework Programme (FP7/20072013) under grant agreement N. 323047 (the ARISTOTEL project). Part of this work was also supported by the "Complex Mechanical Systems Dynamics" Chair - Airbus Group Foundation and the engineering school Arts et Metiers ParisTech. The authors gratefully acknowledge the contribution of ARISTOTEL's partners, specifically the staff at the University of Liverpool, where the piloted flight simulation tests that complemented the analysis of this work were performed.

\section{References}

${ }^{1}$ Pavel, M. D., Jump, M., Dang-Vu, B., Masarati, P., Gennaretti, M., Ionita, A., Zaichik, L., Smaili, H., Quaranta, G., Yilmaz, D., Jones, M., Serafini, J., and Malecki, J., "Adverse Rotorcraft Pilot Couplings-Past, Present and Future Challenges," Progress in Aerospace Sciences, Vol. 62, October 2013, pp. 1-51, doi:10.1016/j.paerosci.2013.04.003.

${ }^{2}$ Pavel, M. D., Masarati, P., Gennaretti, M., Jump, M., Zaichik, L., Dang-Vu, B., Lu, L., Yilmaz, D., Quaranta, G., Ionita, A., and Serafini, J., "Practices to Identify and Preclude Adverse Aircraft-and-RotorcraftPilot Couplings-A Design Perspective," Progress in Aerospace Sciences, Vol. 76, 2015, pp. 55-89, doi:10.1016/j.paerosci.2015.05.002.

${ }^{3}$ McRuer, D. T., Aviation Safety and Pilot Control: Understanding and Preventing Unfavourable Pilot-Vehicle Interactions, National Research Council, National Academy Press, Washington, DC, 1997.

${ }^{4}$ Mitchell, D. G., and Klyde, D. H., "Identifying a Pilot-Induced Oscillation Signature: New Techniques Applied to Old Problems," Journal of Guidance, Control, and Dynamics, Vol. 31, (1), 2008, pp. 215-224, doi:10.2514/1.31470.

${ }^{5}$ Dieterich, O., Götz, J., DangVu, B., Haverdings, H., Masarati, P., Pavel, M. D., Jump, M., and Gennaretti, M., "Adverse Rotorcraft-Pilot Coupling: Recent Research Activities in Europe," Proceedings of the 34th European Rotorcraft Forum, Liverpool, UK, September 16-19, 2008.

${ }^{6}$ AGARD, "PIO Workshop following Active Control Technology: Applications and Lessons Learned," CP 560, AGARD, 1995.

${ }^{7}$ Klyde, D. H., and Mitchell, D. G., "A PIO Case Study-Lessons Learned through Analysis," AIAA-2005-5813, Proceedings of the AIAA Atmospheric Flight Mechanics Conference, San Francisco, CA, August 15-18, 2005.

${ }^{8}$ Perng, J.-W., "Application of Parameter Plane Method to PilotInduced Oscillations," Aerospace Science and Technology, Vol. 23, (1), December 2012, pp. 140-145, doi:10.1016/j.ast.2011.06.006.

${ }^{9}$ Weltz, G., Shweyk, K., and Murray, D., "Application of New and Standard Pilot-Induced Oscillation (PIO) Analysis Methods to Flight Test Data of the C-17 Transport Aircraft," AIAA-2007-6387, Proceedings of the AIAA Atmospheric Flight Mechanics Conference and Exhibit, Hilton Head, SC, August 20-23, 2007.

${ }^{10}$ Mitchell, D. G., and Klyde, D. H., "Recommended Practices for Exposing Pilot-Induced Oscillations or Tendencies in the Development Process," AIAA-2004-6810, Proceedings of the USAF Developmental Test and Evaluation Summit, Woodland Hills, CA, November 16-18, 2004, pp. 1-20. 
${ }^{11}$ Hamel, P. G., "Rotorcraft-Pilot Coupling-A Critical Issue for Highly Augmented Helicopters?" Proceedings of the AGARD-FVP Symposium “Advances in Rotorcraft Technology," Ottawa, Canada, May 27-30, 1996.

${ }^{12}$ Ockier, C. J., "Pilot Induced Oscillations in Helicopters-Three Case Studies," IB 111-96/12, German Aerospace Center (DLR), Braunschweig, Germany, 1996.

${ }^{13}$ Walden, R. B., "A Retrospective Survey of Pilot-Structural Coupling Instabilities in Naval Rotorcraft," American Helicopter Society 63rd Annual Forum Proceedings, Virginia Beach, VA, May 1-3, 2007, pp. 1783-1800.

${ }^{14}$ Parham, T., Jr., Popelka, D., Miller, D. G., and Froebel, A. T., "V22 Pilot-in-the-Loop Aeroelastic Stability Analysis," American Helicopter Society 47th Annual Forum Proceedings, Phoenix, AZ, May 6-8, 1991.

${ }^{15}$ Muscarello, V., Quaranta, G., and Masarati, P., "The Role of Rotor Coning in Helicopter Proneness to Collective Bounce," Aerospace Science and Technology, Vol. 36, July 2014, pp. 103-113, doi:10.1016/j.ast.2014.04.006.

${ }^{16}$ Lantzsch, R., Hamers, M., and Wolfram, J., "Flight Control and Handling Qualities Evaluations Considering Air Resonance," Journal of the American Helicopter Society, 59, 022001 (2014).

${ }^{17}$ Dryfoos, J. B., Kothmann, B. D., and Mayo, J., "An Approach to Reducing Rotor-Body Coupled Roll Oscillations on the RAH-66 Comanche Using Modified Roll Rate Feedback," American Helicopter Society 55th Annual Forum Proceedings, Montreal, Canada, May 25-27, 1999, pp. 1127-1140.

${ }^{18}$ Muscarello, V., Masarati, P., Quaranta, G., Lu, L., Jump, M., and Jones, M., "Investigation of Adverse Aeroelastic Rotorcraft-Pilot Coupling Using Real-Time Simulation," Paper no. 193, American Helicopter Society 69th Annual Forum Proceedings, Phoenix, AZ, May 21-23, 2013.

${ }^{19}$ Jones, M., Jump, M., Lu, L., Yilmaz, D., Pavel, M. D., Masarati, P., Quaranta, G., and Muscarello, V., "Exposing Rotorcraft Pilot Couplings Using Flight Simulation," Proceedings of the 39th European Rotorcraft Forum, Moscow, Russia, September 3-6, 2013.

${ }^{20}$ Cameron, N., and Padfield, G. D., "Handling Qualities Degradation in Tilt-Rotor Aircraft Following Flight Control System Failures," Proceedings of the 30th European Rotorcraft Forum, Marseilles, France, September 14-16, 2004.

${ }^{21}$ Anonymous, "Performance Specification, Handling Qualities Requirements for Military Rotorcraft," ADS 33-E-PRF, U.S. Army AMCOM, Redstone, AL, 2000.

${ }^{22}$ Muscarello, V., Quaranta, G., Masarati, P., Lu, L., Jones, M., and Jump, M., "Prediction and Simulator Verification of Roll/Lateral Adverse Aeroservoelastic Rotorcraft-Pilot Couplings," Journal of Guidance, Control, and Dynamics, Vol. 39, (1), 2016, pp. 42-60, doi:10.2514/1.G001121.

${ }^{23}$ Gandhi, F., and Chopra, I., "An Analytical Model for a Nonlinear Elastomeric Lag Damper and Its Effect on Aeromechanical Stability in Hover," Journal of the American Helicopter Society, Vol. 39, (4), October 1994, pp. 59-69.

${ }^{24}$ Milgram, J. H., and Chopra, I., "Air Resonance of Hingeless Rotor Helicopters in Trimmed Forward Flight," Journal of the American Helicopter Society, Vol. 39, (4), October 1994, pp. 46-58.

${ }^{25}$ Donham, R. E., Cardinale, S. V., and Sachs, I. B., "Ground and Air Resonance Characteristics of a Soft In-Plane Rigid-Rotor System," Journal of the American Helicopter Society, Vol. 14, (4), October 1969, pp. 33-41.

${ }^{26}$ Xiao-Gu, Z., "Physical Understanding of Helicopter Air and Ground Resonance," Journal of the American Helicopter Society, Vol. 31, (4), October 1986, pp. 4-11.
${ }^{27}$ Pavel, M. D., "Modeling Lead-Lag Dynamics for Rotorcraft-PilotCouplings Investigation," 66th Annual Forum of the American Helicopter Society 66th Annual Forum Proceedings, Phoenix, AZ, May 11-13, 2010.

${ }^{28}$ Masarati, P., Muscarello, V., and Quaranta, G., "Linearized Aeroservoelastic Analysis of Rotary-Wing Aircraft," Proceedings of the 36th European Rotorcraft Forum, Paris, France, September 7-9, 2010, pp. 099.1-099.10.

${ }^{29}$ Masarati, P., Muscarello, V., Quaranta, G., Locatelli, A., Mangone, D., Riviello, L., and Viganò, L., "An Integrated Environment for Helicopter Aeroservoelastic Analysis: The Ground Resonance Case," Proceedings of the 37th European Rotorcraft Forum, Gallarate, Italy, September 13-15, 2011, pp. 177.1-177.12.

${ }^{30}$ Muscarello, V., Masarati, P., and Quaranta, G., "Robust Stability Analysis of Adverse Aeroelastic Roll/Lateral Rotorcraft-Pilot Couplings," Journal of the American Helicopter Society, 62, 022003 (2017), doi:10.4050/JAHS.62.022003.

${ }^{31}$ Quaranta, G., Muscarello, V., and Masarati, P., "Lead-Lag Damper Robustness Analysis for Helicopter Ground Resonance," Journal of Guidance, Control, and Dynamics, Vol. 36, (4), July 2013, pp. 11501161, doi:10.2514/1.57188.

${ }^{32}$ Allen, R. W., Jex, H. R., and Magdaleno, R. E., "Manual Control Performance and Dynamic Response During Sinusoidal Vibration," TR 73-78, Aerospace Medical Research Laboratory, October 1973.

${ }^{33}$ Jex, H. R., and Magdaleno, R. E., "Biomechanical Models for Vibration Feedthrough to Hands and Head for a Semisupine Pilot," Aviation, Space, and Environmental Medicine, Vol. 49, (1-2), 1978, pp. 304-316.

${ }^{34}$ Höhne, G., "Computer Aided Development of Biomechanical Pilot Models," Aerospace Science and Technology, Vol. 4, (1), January 2000, pp. 57-69, doi:10.1016/S1270-9638(00)00117-6.

${ }^{35}$ Masarati, P., Quaranta, G., Zaichik, L., Yashin, Y., Desyatnik, P., Pavel, M. D., Venrooij, J., and Smaili, H., "Biodynamic Pilot Modelling for Aeroelastic A/RPC," Proceedings of the 39th European Rotorcraft Forum, Moscow, Russia, September 3-6, 2013.

${ }^{36}$ McRuer, D. T., Graham, D., Kendel, E., and Resiener, W. J., "Human Pilot Dynamics in Compensatory Systems," TR 65-15, Air Force Flight Dynamics Laboratory, 1965.

${ }^{37}$ Masarati, P., Quaranta, G., and Zanoni, A., "Dependence of Helicopter Pilots' Biodynamic Feedthrough on Upper Limbs' Muscular Activation Patterns," Proceedings of Institute of Mechanical Engineering, Part K: Journal of Multibody Dynamics, Vol. 227, (4), December 2013, pp. 344-362, doi:10.1177/1464419313490680.

${ }^{38}$ Masarati, P., Quaranta, G., and Zanoni, A., "A Detailed Biomechanical Pilot Model for Multi-Axis Involuntary Rotorcraft-Pilot Couplings," Proceedings of the 41st European Rotorcraft Forum, Munich, Germany, September 1-4, 2015.

${ }^{39}$ Zanoni, A., and Muscarello, V., "Helicopter Collective Bounce Proneness: Which Are the Good, the Bad (and the Ugly!) Pilot Biometrics?" Proceedings of the 8th ECCOMAS Thematic Conference on Multibody Dynamics, Prague, Czech Republic, June 19-22, 2017.

${ }^{40}$ Pitt, D. M., and Peters, D. A., "Theoretical Prediction of DynamicInflow Derivatives," Vertica, Vol. 5, (1), 1981, pp. 21-34.

${ }^{41}$ Padfield, G. D., Helicopter Flight Dynamics: The Theory and Application of Flying Qualities and Simulation Modelling, Blackwell Publishing, Oxford, UK, 2007.

${ }^{42}$ Serafini, J., Gennaretti, M., Masarati, P., Quaranta, G., and Dieterich, O., "Aeroelastic and Biodynamic Modeling for Stability Analysis of Rotorcraft-Pilot Coupling Phenomena," Proceedings of the 34th European Rotorcraft Forum, Liverpool, UK, September 16-19, 2008.

${ }^{43}$ Gennaretti, M., Serafini, J., Masarati, P., and Quaranta, G., "Effects of Biodynamic Feedthrough in Rotorcraft-Pilot Coupling: Collective 
Bounce Case," Journal of Guidance, Control, and Dynamics, Vol. 36, (6), 2013, pp. 1709-1721, doi:10.2514/1.61355.

${ }^{44}$ Quaranta, G., Tamer, A., Muscarello, V., Masarati, P., Gennaretti, M., Serafini, J., and Colella, M. M., "Rotorcraft Aeroelastic Stability Using Robust Analysis," CEAS Aeronautical Journal, Vol. 5, (1), March 2014, pp. 29-39, doi:10.1007/s13272-013-0082-z.

${ }^{45}$ Quaranta, G., Masarati, P., and Venrooij, J., "Impact of Pilots' Biodynamic Feedthrough on Rotorcraft by Robust Stability," Journal of Sound and Vibration, Vol. 332, (20), September 2013, pp. 4948-4962, doi:10.1016/j.jsv.2013.04.020.

${ }^{46}$ Desoer, C., and Wang, Y., "On the Generalized Nyquist Stability Criterion," IEEE Transactions on Automatic Control, Vol. 25, (2), 1980, pp. 187-196.
${ }^{47}$ Friedland, B., Control System Design: An Introduction to StateSpace Methods, McGraw-Hill, New York, NY, 1987.

${ }^{48}$ Tod, G., Pavel, M. D., Malburet, F., Gomand, J., and Barre, P.-J., "Understanding Pilot Biodynamical Feedthrough Coupling in Helicopter Adverse Roll Axis Instability via Lateral Cyclic Feedback Control," Aerospace Science and Technology, Vol. 59, December 2016, pp. 18-31.

${ }^{49}$ Pausder, H. J., and Blanken, C. L., "Investigation of the Effects of Bandwidth and Time Delay on Helicopter Roll-Axis Handling Qualities," Proceeding of the 18th European Rotorcraft Forum, Avignon, France, September 15-18, 1992.

${ }^{50}$ Bielawa, R. L., "Notes Regarding Fundamental Understandings of Rotorcraft Aeroelastic Instability," Journal of the American Helicopter Society, Vol. 32, (4), 1987, pp. 4-15. 